\title{
NO-Sensitive Guanylate Cyclase Isoforms NO-GC1 and NO-GC2 Contribute to Noise-Induced Inner Hair Cell Synaptopathy
}

\author{
Dorit Möhrle, ${ }^{1}$ Katrin Reimann, ${ }^{1}$ Steffen Wolter, ${ }^{1}$ Markus Wolters, Ksenya Varakina, \\ Evanthia Mergia, Nicole Eichert, Hyun-Soon Geisler, Peter Sandner, Peter Ruth, \\ Andreas Friebe, Robert Feil, Ulrike Zimmermann, Doris Koesling, Marlies Knipper, \\ and Lukas Rüttiger
}

\begin{abstract}
Department of Otolaryngology, Head and Neck Surgery, Hearing Research Centre Tübingen, Molecular Physiology of Hearing, University of Tübingen, Tübingen (D.M., K.R., S.W., K.V., N.E., H.-S.G., U.Z., M.K., L.R.), Interfaculty Institute of Biochemistry, University of Tübingen, Tübingen (M.W., R.F.), Department of Pharmacology and Toxicology, University of Bochum, Bochum (E.M., D.K.), Bayer AG, Drug Discovery Pharma Research Centre Wuppertal, Wuppertal (P.S.), Department of Pharmacology, Toxicology and Clinical Pharmacy, Institute of Pharmacy, University of Tübingen, Tübingen (P.R.), and Department of Physiology, University of Würzburg, Würzburg (A.F.), Germany
\end{abstract}

Received February 7, 2017; accepted July 18, 2017

\section{ABSTRACT}

Nitric oxide (NO) activates the NO-sensitive soluble guanylate cyclase (NO-GC, sGC) and triggers intracellular signaling pathways involving cGMP. For survival of cochlear hair cells and preservation of hearing, NO-mediated cascades have both protective and detrimental potential. Here we examine the cochlear function of mice lacking one of the two NO-sensitive guanylate cyclase isoforms [NO-GC1 knockout (KO) or NO-GC2 $\mathrm{KO}$. The deletion of NO-GC1 or NO-GC2 did not influence electromechanical outer hair cell $(\mathrm{OHC})$ properties, as measured by distortion product otoacoustic emissions, neither before nor after noise exposure, nor were click- or noise-burst-evoked auditory brainstem response thresholds different from controls. Yet inner hair cell $(\mathrm{IHC})$ ribbons and auditory nerve responses showed significantly less deterioration in NO-GC1 $\mathrm{KO}$ and NO-GC2 KO mice after noise exposure. Consistent with a selective role of NO-GC in IHCs, NO-GC $\beta 1$ mRNA was found in isolated $\mathrm{IHCs}$ but not in OHCs. Using transgenic mice expressing the fluorescence resonance energy transfer-based cGMP biosensor cGi500, NO-induced elevation of cGMP was detected in real-time in IHCs but not in OHCs. Pharmacologic long-term treatment with a NO-GC stimulator altered auditory nerve responses but did not affect $\mathrm{OHC}$ function and hearing thresholds. Interestingly, NO-GC stimulation exacerbated the loss of auditory nerve response in aged animals but attenuated the loss in younger animals. We propose NO-GC2 and, to some degree, NO-GC1 as targets for early pharmacologic prevention of auditory fiber loss (synaptopathy). Both isoforms provide selective benefits for hearing function by maintaining the functional integrity of auditory nerve fibers in early life rather than at old age.

\section{Introduction}

The dramatic shift in societal demographics will soon significantly increase the number of older people with hearing deficits. Much of the aging population experiences difficulties in perceiving speech in noise, even if audiometric thresholds are still normal or at least appear to be within the normal

This work was supported by the Deutsche Forschungsgemeinschaft [Grants FOR 2060 project FE 438/6-1, FR 1725/3-1, RU 713/3-2], Action on Hearing Loss [RNID Grant 54], and University of Tübingen, Tübingen, Germany [Fortüne 2339-0-0].

${ }^{1}$ D.M., K.R. and S.W. contributed equally to this work.

https://doi.org/10.1124/mol.117.108548. range (hidden hearing loss) (Füllgrabe et al., 2015). Hidden hearing loss has been previously linked to progressing cochlear synaptopathy, as has been observed in aging animals (Bharadwaj et al., 2014; Bramhall et al., 2015) and humans (Viana et al., 2015) and has come into focus recently in the search for human therapeutic interventions.

Nitric oxide (NO) is synthesized by NO synthase (NOS) and is thought to influence inner ear function via different pathways. It activates two different isoforms of the NOsensitive guanylate cyclase (NO-GC), which forms cyclic guanosine monophosphate (cGMP) (Takumida and Anniko, 2002). The molecular mechanisms and importance of NO in

ABBREVIATIONS: ABR, auditory brainstem response; ANOVA, analysis of variance; CFP, cyan fluorescent protein; cGK, cGMP-dependent protein kinase; CtBP2, C-terminal-binding protein 2; DEA/NO, 2-(N,N-diethylamino)-diazenolate-2-oxide; DPOAE, distortion product otoacoustic emission; FRET, fluorescence resonance energy transfer; GC-A, guanylate cyclase A; HCN channel, hyperpolarization-activated cyclic nucleotide-gated cation channel; IHC, inner hair cell; KCNQ4, potassium voltage-gated channel subfamily KQT member 4; KO, knockout; NMDA, N-methyl-Daspartate; NO, nitric oxide; NO-GC, NO-sensitive guanylate cyclase; NOS, NO synthase; OHC, outer hair cell; PAR, poly (ADP-ribose); PARP, poly (ADP-ribose) polymerase; PPAR, peroxisome proliferator-activated receptor; RT-PCR, reverse transcription polymerase chain reaction; sGC, soluble guanylate cyclase; SPL, sound pressure level; SPLrms, sound pressure level root-mean-square; WT, wild-type; YFP, yellow fluorescent protein. 
auditory function remain controversial. NO has been predicted to damage cochlear function, as has been observed, for example, after exposure to loud noise (Shi et al., 2002; Ohinata et al., 2003); however, NO has also been suggested to protect hair cells from damage through a NO-GC-induced counteraction of stressor-triggered $\mathrm{Ca}^{2+}$ increase, as shown for OHCs and IHCs in in vitro studies (Shen et al., 2003, 2005, 2006; Yukawa et al., 2005; Takeda-Nakazawa et al., 2007). To date, the function of NO-GC in hearing has never been specifically addressed in the mature auditory system. Studying global NO-GC KO mice is suboptimal because a complete absence of NO-GC, and therefore a lack of NO-induced cGMP production, is accompanied by elevated blood pressure and fatal gastrointestinal obstruction with postnatal lethality after 3 to 4 weeks (Friebe et al., 2007; Groneberg et al., 2016) when hearing in rodents is still maturing (Sanes and Constantine-Paton, 1985; Narui et al., 2009).

Therefore, to illuminate the role of the NO/NO-GC/ cGMP/cGMP-dependent protein kinase (cGK) signaling cascade for audition, we investigated two transgenic mouse strains, each lacking one of the two isoforms of the heterodimeric NO-GC protein, which consists of the $\beta_{1}$-subunit that forms dimers with the $\alpha_{1}$-subunit and $\alpha_{2}$-subunit for NO-GC1 and NO-GC2 isoforms, respectively (Russwurm and Koesling, 2002). The NO-GC1 and NO-GC2 isoforms (Koesling et al., 2004) do not differ in their enzymatic or regulatory properties (Russwurm et al., 1998) and have been shown to be expressed in similar amounts in the central nervous system (Mergia et al., 2003).

In the present study, hearing function was analyzed for the first time in the previously generated NO-GC1 KO and NO-GC2 KO mice (Mergia et al., 2006). We compared the morphologic and functional biomarkers in these mice (Rüttiger et al., 2017). Specifically, the detection of surface expression of the potassium voltage-gated channel subfamily KQT member 4 (KCNQ4), which accounts for the predominant $\mathrm{K}^{+}$conductance $\left(I_{\mathrm{K}, \mathrm{n}}\right)$ of mature OHCs (Marcotti and Kros, 1999), is used as a marker for OHCs (Winter et al., 2007). Quantification of the presynaptic ribbon structures at the base of IHCs, which can be stained by antibodies directed against the RIBEYE protein C-terminal-binding protein 2 (CtBP2), provides an approximate metric for the number of IHC afferent innervations (Kujawa and Liberman, 2009; Buran et al., 2010). A change in numbers of IHC ribbon synapses is related to altered auditory brainstem response (ABR) wave responses (Kujawa and Liberman, 2009; Jaumann et al., 2012; Zuccotti et al., 2012; Singer et al., 2013; Wichmann and Moser, 2015; Chumak et al., 2016). Therefore, IHC ribbon counts are used to evaluate an attenuation of the summed auditory nerve response amplitude (Kujawa and Liberman, 2009; Buran et al., 2010). The detection of these biomarkers using high-resolution fluorescence microscopy was combined with various functional approaches [auditory brainstem response (ABR); distortion product otoacoustic emission (DPOAE); fine-structure analysis of $\mathrm{ABR}$ wave; fluorescence resonance energy transfer (FRET)]. Recently, pharmacologic compounds have been developed that allow modulation of the activity of NO-GC in a highly selective, NO-independent manner. These compounds can be used as pharmacologic tools to investigate the NO/cGMP pathway and furthermore as potential therapeutic agents (Stasch et al., 2002a; Evgenov et al., 2006). We therefore investigated the effect of the NO-GC stimulator BAY 41-8543 on hearing and noise-induced neurodegeneration in young and aged rats. The present study provides the first evidence for a role of NO-GC1 and NO-GC2 in noise-induced cochlear IHC synaptopathy, implicating both isoforms as candidate targets for future early therapeutic interventions in hidden hearing loss in the young.

\section{Materials and Methods}

\section{Animals}

Generation of NO-GC Isoform-Specific Knockout Mice. The NO-GC1 KO and NO-GC2 KO mice were generated by breeding mice carrying the floxed exon 4 of the $\alpha_{1^{-}}$or $\alpha_{2}$-subunit, respectively, with an EIIa/Cre mouse line (Lakso et al., 1996), resulting in the deletion of either the $\alpha_{1}$ - or the $\alpha_{2}$-subunit. The loss of the $\alpha_{1}$ - or $\alpha_{2}$-subunit was confirmed by Western blot analysis using subunit-specific antibodies (Mergia et al., 2006). Adult (1.1- to 4.2-month-old) female and male NO-GC1 KO and NO-GC2 KO mice were used, and their wild-type (WT) siblings served as controls.

Generation of cGMP Sensor [R26-cGi500(L1)] mice. Transgenic cGMP sensor [R26-cGi500 (L1)] mice were generated by targeted knock-in into the Rosa26 locus of a Cre recombinase-activated expression cassette encoding the cGMP sensor cGi500 driven by the ubiquitous cytomegalovirus early enhancer/chicken $\beta$-actin/ $\beta$-globin (CAG) promoter (R26-CAG-cGi500 mice) (Thunemann et al., 2013b).

Wistar Rats. We purchased female Wistar rats weighing 200-250 g from Charles River Laboratories (Research Models and Services, Germany GmbH, Sulzfeld, Germany) and housed them for up to 2 years in the animal care facility of the ENT clinic in Tübingen (Germany).

The care and use of the animals and the experimental protocol were reviewed and approved by the University of Tübingen, Veterinary Care Unit, and the Animal Care and Ethics Committee of the regional board of the Federal State Government of Baden-Württemberg, Germany, and followed the guidelines of the EU Directive 2010/63/EU for animal experiments. NO-GC isoform-specific mice were generated as previously described (Mergia et al., 2006). NO-GC isoform-specific and R26-cGi500(L1) mice were bred in a central mouse breeding unit of the FOR 2060 research unit located in the animal facility of the Interfaculty Institute of Biochemistry in Tübingen.

Hearing Measurements: ABR and DPOAE. The ABR, evoked by short-duration sound stimuli, represents the summed activity of neurons in distinct anatomic structures or nuclei along the ascending auditory pathway (Burkard and Don, 2007) and is measured by averaging the evoked electrical response recorded via subcutaneous cranial electrodes. ABRs to click and noise-burst stimuli and the DPOAEs for $\mathrm{f} 2=1.24 \times \mathrm{f} 1$ and $\mathrm{L} 2=\mathrm{L} 1-10 \mathrm{~dB}$ were recorded in anesthetized adult animals. All physiologic recordings were performed with the animals under anesthesia [mice: $75 \mathrm{mg} / \mathrm{kg}$ ketamin hydrochloride (Ketavet; Pfizer, Karlsruhe, Germany), $5 \mathrm{mg} / \mathrm{kg}$ xylazine hydrochloride (Rompun 2\%; Bayer, Leverkusen, Germany), $0.2 \mathrm{mg} / \mathrm{kg}$ atropine (Atropinsulfat; B. Braun, Melsungen, Germany); rats: $75 \mathrm{mg} / \mathrm{kg}$ ketamin hydrochloride, $5 \mathrm{mg} / \mathrm{kg}$ xylazine hydrochloride, or $0.075 \mathrm{mg} / \mathrm{kg}$ fentanyl (Fentanyl-ratiopharm; ratiopharm $\mathrm{GmbH}$, Ulm, Germany), $0.4 \mathrm{mg} / \mathrm{kg}$ medetomidin hydrochloride (Sedator; Eurovet Animal Health B.V., Bladel, Netherlands)] in a soundproof chamber (IAC, Niederkrüchten, Germany) as previously described (Engel et al., 2006). In short, ABR thresholds were determined with click (100 $\mu \mathrm{s})$, and noise-burst stimuli ( $1 \mathrm{~ms}$ duration). OHC function was assessed by the DP-gram of the $2 *$ f1-f2 DPOAE (Knipper et al., 2000; Engel et al., 2006).

Noise Exposure. Acoustic trauma was induced by exposing mice to broadband noise (noise-exposed, $8-16 \mathrm{kHz}, 120 \mathrm{~dB}$ sound pressure level root-mean-square (SPLrms) for 1 hour) as previously described (Jaumann et al., 2012) while the mice were under anesthesia (see 
preceding), and small volumes of anesthetics were administered subcutaneously every 20 minutes to maintain anesthesia. In noiseexposed mice, the degree of the ABR threshold shift was measured approximately 30 minutes after noise exposure to estimate temporary threshold shifts and again after 7 days when noise-induced permanent threshold shifts had settled and further recovery from damage would no longer be expected (Liberman, 1980). Rats were exposed to moderate broadband noise (noise-exposed, 8-16 kHz, $100 \mathrm{~dB}$ SPLrms for 2 hours), causing a temporary threshold shift (Kujawa and Liberman, 2006; Kujawa and Liberman, 2009; Lin et al., 2011; Singer et al., 2013) while they were under anesthesia (see preceding). Supplemental doses of anesthetics were administered after 1 hour or if the toe reflex recovered. In noise-exposed rats, the degree of the ABR threshold shift was measured after approximately 30 minutes and again 4 weeks after noise exposure. Sham-exposed animals were anesthetized and placed in the reverberating chamber but not exposed to the acoustic stimulus (i.e., the speaker remained turned off). The sham-exposed animals retained completely normal hearing.

Tissue Preparation. For immunohistochemistry, cochleae were isolated, fixed by immersion in Zamboni's fixative or $2 \%$ paraformaldehyde, $125 \mathrm{mM}$ sucrose in $100 \mathrm{mM}$ phosphate-buffered saline, $\mathrm{pH} 7.4$, for 2 hours, and then decalcified for 45 minutes in RDO rapid decalcifier (Apex Engineering Products Corporation, Aurora, IL, USA) as previously described (Knipper et al., 1999; Zuccotti et al., 2012; Duncker et al., 2013; Singer et al., 2013), cryosectioned at $10 \mu \mathrm{m}$, and mounted on SuperFrost*/Plus microscope slides (R. Langenbrinck Labor- u. Medizintechnik, Emmendingen, Germany) before storage at $-20^{\circ} \mathrm{C}$.

Immunohistochemistry. For immunohistochemistry, mouse cochlear sections were stained as previously described (Tan et al., 2007; Zuccotti et al., 2012; Singer et al., 2013). Antibodies against prestin (rabbit, diluted 1:3000) (Weber et al., 2002), KCNQ4 (mouse, diluted 1: 50; StressMarq, Victoria, BC, Canada) (Kharkovets et al., 2006), CtBP2/RIBEYE (rabbit, diluted 1:1500; ARP American Research Products, Inc., Waltham, MA, USA) (Uthaiah and Hudspeth, 2010) were used. For double labeling studies, both antibodies were simultaneously incubated for identical periods. Sections were viewed as previously described (Zampini et al., 2010) using an Olympus BX61 microscope (Olympus, Hamburg, Germany) equipped with epifluorescence illumination. Images were acquired using an Olympus XM10 CCD monochrome camera and analyzed with cellSens Dimension software (OSIS GmbH, Münster, Germany). To increase spatial resolution, slices were imaged over $15 \mu \mathrm{m}$ within an image stack along the $z$-axis ( $z$-stack), followed by three-dimensional deconvolution using cellSens Dimension's built-in algorithm. We repeated each immunohistochemical labeling three times in three independent experiments.

mRNA Isolation and Reverse Transcription-Polymerase Chain Reaction. For reverse transcription polymerase chain reaction (RT-PCR) analysis, cochlear hair cells from 28-day-old mice were collected with micropipettes as previously described (Michna et al., 2003; Knirsch et al., 2007) and frozen in liquid nitrogen. cDNA synthesis was performed using the iScript cDNA Synthesis Kit (Bio-Rad, Munich, Germany) (Duncker et al., 2013). Duplex RT-PCR analysis was performed on cDNA of OHCs and IHCs using the QIAGEN Sensiscript RT Kit (QIAGEN, Hilden, Germany) following the manufacturer's instructions with the iCycler $\mathrm{iQ}$ detection system (Bio-Rad). A 536-bp fragment of the NO-GC $\beta 1$-subunit spanning exon 10 (accession number NM_017469.4, position 1401-1936) was amplified by RT-PCR with the oligonucleotides 5'-ATCCTCTTCAGCGGCATTGTG-3' and 5'-TGCATTGGTTCCTTCTTGCCC-3'. After PCR purification (QIAGEN PCR Purification Kit), a 446-bp fragment of NO-GC was amplified by nested RT-PCR with the oligonucleotides 5'-TCTCCTCAACGATCTCTACACC-3' and 5'-CCTTCTTGCCCTTCATAGACAC-3' . In addition, a 702-bp fragment of guanylate cyclase A (GC-A) (accession number BC110659.1, position 1926-2627) was amplified by RT-PCR with the oligonucleotides 5'-TGT GAAACGTGTGAACCGGA-3' and 5'-AGGCGGATCTGTTGAAAGGG-3'.
After PCR purification, a 467-bp fragment of GC-A was amplified by nested RT-PCR with the oligonucleotides 5'-TGTGCAGAATGAGCACTTGACC-3' and 5'-CCAAACCTTCCACATAGAAGACCC-3'. The PCR program, according to the manufacturer's instructions, included an initial activation step at $95^{\circ} \mathrm{C}$ for 3 minutes, followed by 35 cycles of a 30 -second denaturing step at $95^{\circ} \mathrm{C}$, a 30 -second combined annealing and extension step at $59^{\circ} \mathrm{C}$, and 45 seconds at $72^{\circ} \mathrm{C}$, ending with 5 minutes at $72^{\circ} \mathrm{C}$. For nested RT-PCR, the PCR program included an initial activation step at $95^{\circ} \mathrm{C}$ for 3 minutes, followed by 35 cycles of a 30 -second denaturing step at $95^{\circ} \mathrm{C}$, a 30 -second combined annealing/extension step at $58^{\circ} \mathrm{C}$, and 30 seconds at $72^{\circ} \mathrm{C}$, ending with 5 minutes at $72^{\circ} \mathrm{C}$. The PCR fragments were extracted (QIAGEN Gel Extraction Kit) and sequenced to confirm NO-GC and GC-A specificity.

Fluorescence Resonance Energy Transfer Measurements. NO-induced changes in cellular cGMP concentrations were measured by fluorescence resonance energy transfer (FRET) microscopy. Cochlear whole-mount preparations were isolated from 7- to 14-day-old R26-cGi500(L1) mice (Thunemann et al., 2013b), a mouse line that ubiquitously expresses the FRET-based cGMP biosensor cGi500 (cGMP-indicator with an $\mathrm{EC}_{50}$ of $500 \mathrm{nM}$ cGMP) (Russwurm et al., 2007). Imaging was performed with a spinning disk microscope (upright Axio Examiner Z1; Zeiss, Jena, Germany) equipped with a CSU-X1 (Yokogawa, Ratingen, Germany), 445-nm laser, QuantEM: 512SC EMCCD camera (Photometrics, Tuscon, AZ, USA), and DualView DV2 beam splitter (Photometrics) for simultaneous imaging of cyan fluorescent protein (CFP) and yellow fluorescent protein (YFP). The setup was controlled with VisiView software (Visitron Systems, Puchheim, Germany). The tissue was continuously superfused with either buffer $\left(140 \mathrm{mM} \mathrm{NaCl}, 5 \mathrm{mM} \mathrm{KCl}, 2.5 \mathrm{mM} \mathrm{CaCl}_{2}\right.$, $1.2 \mathrm{mM} \mathrm{MgCl}_{2}, 5 \mathrm{mM}$ HEPES, $5 \mathrm{mM}$ glucose, $\mathrm{pH}$ 7.4) or $500 \mathrm{nM} 2$-(N, $\mathrm{N}$-diethylamino)-diazenolate-2-oxide (DEA/NO)-containing buffer at room temperature. Fluorescence of CFP and YFP was simultaneously recorded. Fiji (Schindelin et al., 2012) was used to extract intensity values from different regions of the acquired images. Microsoft Excel 2013 (Redmond, WA, USA) and Origin Pro 2016 (OriginLab, Northampton, CA, USA) were used for subsequent background correction, ratio calculation, and amplitude analysis as previously described (Thunemann et al., 2013a).

Drug Application. BAY 41-8543 (2-[1-[(2-fluorophenyl)methyl]1H-pyrazolo[3,4-b]pyridin-3-yl]-5(4-morpholinyl)-4,6-pyrimidine-diamine) was obtained from Bayer AG (Leverkusen, Germany). BAY 41-8543 is a heme-dependent stimulator of NO-GC [soluble guanylate cyclase (sGC) stimulator], increasing the activity of recombinant NO-GC dosedependently (Stasch et al., 2002b). The substance was pressed into the pellets of standard rat diet at a concentration of $125 \mathrm{mg} / \mathrm{kg}$ by Ssniff (Soest, Germany) to reach the planned consumption of $5 \mathrm{mg}$ of substance per kilogram of rat per day. Administration of the NO-GC stimulator containing diet started on the 3rd day after noise or sham exposure and continued for 25-32 days until the rats were sacrificed. Control groups received an equal quantity of regular diet. The drug concentration of $125 \mathrm{mg} / \mathrm{kg}$ pressed in pellets and planned consumption of $5 \mathrm{mg} / \mathrm{kg}$ per day were based on effective dosages of BAY 41-8543 and pharmacokinetic studies performed with BAY 41-2272 in previous studies.

\section{Data Analysis}

ABR Fine-Structure Analysis. ABR functions were analyzed for consecutive amplitude deflections (waves), with each wave consisting of a starting negative $(n)$ peak and the subsequent positive $(p)$ peak. Peak amplitudes of noise-burst stimulus-evoked ABR (noise ABR) wave I were extracted with customized computer programs as previously described (Rüttiger et al., 2013). ABR peak-to-peak (wave) amplitude input-output growth functions were constructed using Microsoft Excel 2007 (Redmond, WA, USA) for each individual ear and increasing stimulus levels with reference to the ABR thresholds (from 0 to a maximum of $85 \mathrm{~dB}$ above threshold before noise exposure and from 0 to a maximum of $55 \mathrm{~dB}$ above threshold after noise 
exposure for mice). For rats, the "treatment benefit" of the NO-GC stimulator BAY 41-8543 was calculated from click-evoked ABR wave I amplitudes from 40 to $60 \mathrm{~dB}$ above threshold. For individual rats, the $A B R$ wave amplitude before the exposure was subtracted from the amplitude after the exposure, and the resulting differences were subsequently averaged across intensities and rats. To depict the "treatment benefit", the averaged differences of groups without the stimulator BAY 41-8543 were subtracted from groups with the NO-GC stimulator BAY 41-8543, for sham- and noiseexposed rats.

\section{Statistical Analysis}

Results for ABR thresholds, DPOAE thresholds, and ABR finestructure analysis from the two individual ears of each animal were averaged, and the statistical analysis was run based on the number of animals. Unless otherwise stated, all data are presented as group mean with standard deviations (S.D.). Differences in the means were compared for statistical significance either by Student's $t$-test, oneway analysis of variance (ANOVA), two-way ANOVA, or repeated measures ANOVA tests using Microsoft Excel 2007 and 2013 or GraphPad Prism 6.07 (La Jolla, USA). One-way and two-way ANOVA tests were followed by multiple comparison tests with correction for type 1 error after Tukey method or Bonferroni. Noise-burst-evoked ABR hearing thresholds after noise exposure were analyzed by random permutation tests in consideration of small sample sizes to estimate the population mean from samples (resampling by bootstrapping, property mean, 10,000 random samples without replacement). Statistical significance level was $\alpha=0.05$, and resulting $P$ values are reported in the figure legends using the following: $* P \leq$ $0.05, * * P \leq 0.01, * * * P \leq 0.001$, and N.S., not significant.

\section{Results}

NO-GC1 or NO-GC2 Deletion Does not Affect Basal Hearing Thresholds and Outer Hair Cell Function before Noise Exposure. With the goal of investigating the possible role of NO-GC1 or NO-GC2 in hearing, we compared the hearing thresholds in adult mice using ABR measurements as described by Jaumann et al. (2012) and Möhrle et al. (2016). As shown in Fig. 1A, neither NO-GC1 KO mice (13.5 dB $\mathrm{SPL} \pm 3.4 \mathrm{~dB}, n=26$ ears, 13 mice) nor NO-GC2 KO mice (15.2 dB SPL $\pm 4.7 \mathrm{~dB}, n=22$ ears, 11 mice) showed a significant difference in click-evoked ABR thresholds
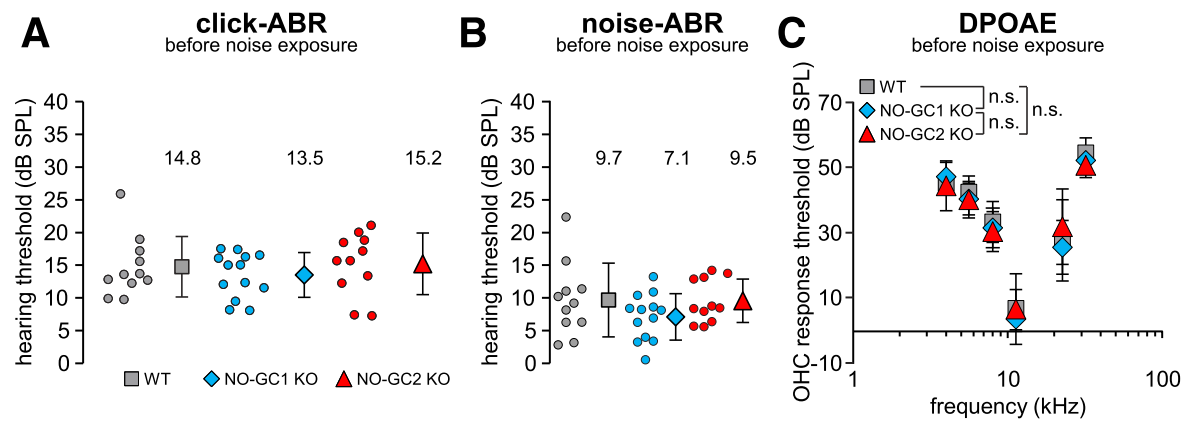

\section{D}

WT
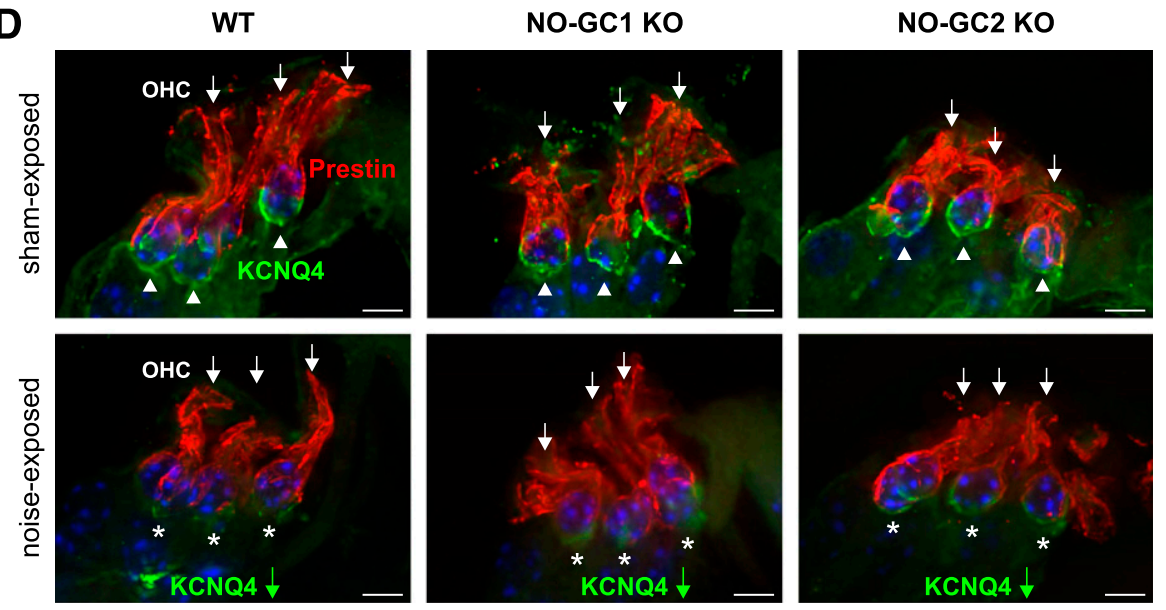

Fig. 1. ABR thresholds, OHC function, and OHC phenotype of NO-GC WT, NO-GC1 KO, and NO-GC2 KO mice. (A and B) Hearing thresholds of unexposed mice assessed from electrical ABR potentials in response to low tone frequency containing (click) and high tone frequency containing (noiseburst) auditory stimuli. (A) Mean \pm S.D. click-evoked ABR thresholds for WT (gray square, single mouse thresholds as gray dots), NO-GC1 KO (blue diamond, single mouse thresholds as blue dots), and NO-GC2 KO mice (red triangle, single mouse thresholds as red dots) were not significantly different (one-way ANOVA: $P=0.5966$ ). (B) Mean \pm S.D. noise-burst-evoked ABR thresholds for WT, NO-GC1 KO, and NO-GC2 KO mice were similar (one-way ANOVA: $P=0.2522$ ). (C) OHC function assessed from ear canal sound pressure changes induced by DPOAEs, which are generated upon electromechanical responses of OHCs. Mean \pm S.D. DPOAE signal thresholds in response to pure tone sounds from 4 to $32 \mathrm{kHz}$ were similar in NO-GC1 KO, NO-GC2 KO, and WT mice (WT vs. NO-GC1 KO, two-way ANOVA: genotype $P=0.1198$; WT vs. NO-GC2 KO, two-way ANOVA: genotype $P=0.5191$ ). (D) The intactness of the OHC phenotype was investigated by immunohistochemical staining for KCNQ4 (green) and the motor protein prestin (red) as markers for OHC viability and their capacity for electromechanical response. Staining for KCNQ4 (green) and prestin (red) in cochlear OHCs of WT, NO-GC1 KO, and NO-GC2 KO mice revealed no obvious differences in OHC structure without noise exposure (upper panel). Noise-induced deterioration of KCNQ4-labeling (indicated by asterisks and arrowheads with and without trauma, respectively) was similar in WT, NO-GC1 KO, and NO-GC2 KO mice (lower panel). After trauma, all mice showed similar loss of KCNQ4. Scale bars, $5 \mu$ m. n.s., not significant. 
compared with WT mice (14.8 dB SPL $\pm 4.6 \mathrm{~dB}, n=22$ ears, 11 mice, one-way ANOVA: $P=0.5966)$. High-frequency regions of the cochlea are known to be most vulnerable to damage (Bohne and Harding, 2000; Harding et al., 2002). Therefore, we also measured ABR thresholds evoked by noiseburst stimuli (Fig. 1B) that contained more energy at higher stimulus frequencies. No difference was found in noise-burstevoked ABR thresholds when comparing WT (9.7 dB SPL \pm $5.6 \mathrm{~dB}, n=22$ ears, 11 mice), NO-GC1 KO (7.1 dB SPL \pm $3.6 \mathrm{~dB}, n=26$ ears, 13 mice), and NO-GC2 KO mice (9.5 dB SPL $\pm 3.3 \mathrm{~dB}, n=22$ ears, 11 mice, one-way ANOVA: $P=0.2522$ ). This finding suggests that NO-GC1 and NO-GC2 deletion did not disturb auditory thresholds.

$\mathrm{OHC}$ electromotility forms the basis of the sound-evoked neural potentials at threshold (Marcon and Patuzzi, 2008). To assess $\mathrm{OHC}$ function, we recorded ear canal sound pressure changes induced by distortion products of the otoacoustic emissions (DPOAEs) (Shera and Guinan, 1999) that are specifically generated upon intact electromechanical responses of OHCs (El-Badry and McFadden, 2007; Rüttiger et al., 2017). We analyzed the frequency-specific thresholds of DPOAE signals from amplitude input-output functions by presenting pure-tone sounds from $\mathrm{f} 2=4-32 \mathrm{kHz}$ and increasing sound level (L1 $=-10-65 \mathrm{~dB}$ SPL) in NO-GC isoform-specific KO mice compared with age-matched WT mice (Fig. 1C). DPOAE thresholds were similar in WT and NO-GC1 KO mice (Fig. 1C, WT: $n=15-16$ ears, 8 mice; NO-GC1 KO: $n=22$ ears, 11 mice, two-way ANOVA: genotype $P=0.1198$, frequency $P<0.0001$, interaction $P=0.7957$ ), as well as in WT and NO-GC2 KO mice (Fig. 1C, NO-GC2 KO: $n=$ 18-20 ears, 10 mice, two-way ANOVA: genotype $P=0.5191$, frequency $P<0.0001$, interaction $P=0.6789$ ). These findings suggest that the electromechanical properties of OHCs are not influenced by deletion of NO-GC1 or NO-GC2. Molecular biomarkers for OHCs include the voltage-dependent $\mathrm{K}^{+}$ channel KCNQ4, which is important for OHC viability (Marcotti and Kros, 1999), and the OHC motor protein prestin, which is encoded by the Slc26a5 gene (Zheng et al., 2000) and is responsible for the electromechanical properties of OHCs. When OHCs in serial cochlear sections from NO-GC1 and NO-GC2 KO mice were stained with antibodies against
KCNQ4 and prestin, no difference was noted in the labeling distribution compared with same-aged WT mice (Fig. 1D), which indicates that in the absence of either NO-GC isoform, OHCs display normal expression profiles of all specific biomarkers (KCNQ4 and prestin) in accordance with normal functional properties.

In conclusion, these findings strongly indicate that neither the NO-GC1 nor the NO-GC2 isoform is engaged in the control of basic hearing thresholds and $\mathrm{OHC}$ function.

\section{NO-GC1 and NO-GC2 Do not Affect Outer Hair Cell} Function after Noise Exposure. NO has been shown to induce cGMP/cGK-dependent counteraction of ATP- or hyposmotic stimulation-induced $\mathrm{Ca}^{2+}$ signaling in isolated OHCs (Shen et al., 2006; Takeda-Nakazawa et al., 2007). If this protective function was mediated by NO-GC also in vivo, we might expect a more pronounced hearing threshold loss after noise exposure when NO-GC1 or NO-GC2 are knocked out. When the sensitivity of otoacoustic emissions by DPOAEs was measured 7-9 days after noise exposure, the elevation of DPOAE thresholds in NO-GC isoform-specific KO mice was similar at all recorded stimulus frequencies to the elevation of thresholds in their age-matched WT controls (Fig. 2A, WT: $n=$ 9-10 ears, 5 mice; NO-GC1 KO: $n=9-10$ ears, 5 mice, two-way ANOVA: genotype $P=0.3488$, frequency $P<0.0001$, interaction $P=0.9615$; NO-GC2 KO: $n=5-8$ ears, 3-4 mice, two-way ANOVA: genotype $P=0.8171$, frequency $P=0.0001$, interaction $P=0.9653$; WT sham-exposed: $n=5-6$ ears, 3 mice vs. noise-exposed, two-way ANOVA: exposure $P<$ 0.0001 , frequency $P<0.0001$, interaction $P=0.0001$; NO-GC1 KO sham-exposed: $n=6$ ears, 3 mice vs. noise-exposed, twoway ANOVA: exposure $P<0.0001$, frequency $P<0.0001$, interaction $P=0.0049$; NO-GC2 KO sham-exposed: $n=5-$ 6 ears, 3 mice vs. noise-exposed, two-way ANOVA: exposure $P<0.0001$, frequency $P<0.0001$, interaction $P=0.0172$, Bonferroni's multiple comparison tests; see Table 1). This result indicates that the noise trauma-induced changes in electromechanical properties of OHCs were not different in WT, NO-GC1 KO, and NO-GC2 KO mice.

In conclusion, this finding indicates that noise-induced suppression of electromechanical properties of OHCs in vivo is not influenced by the deletion of NO-GC1 or NO-GC2.
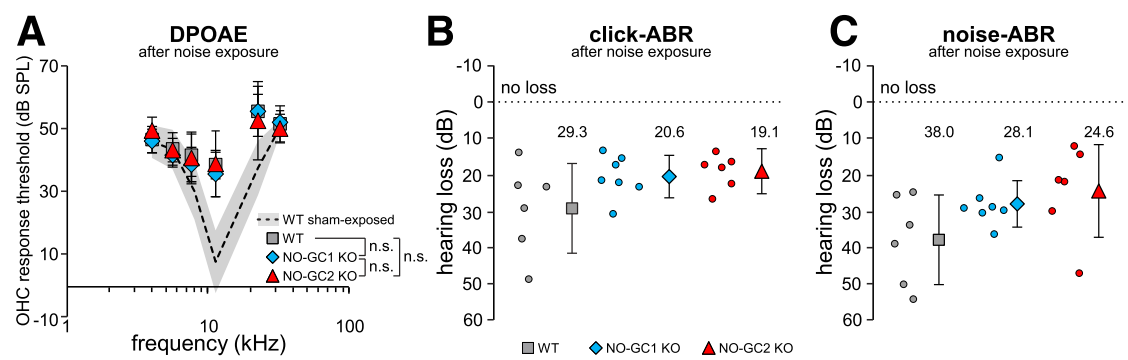

Fig. 2. Effects of exposure to intense noise on OHC function and hearing thresholds by the ABR of NO-GC WT, NO-GC1 KO, and NO-GC2 KO mice. (A) Noise-induced changes of OHC function were assessed from the thresholds of DPOAE signals as a measure for the electromechanical properties of OHCs in response to pure tone sounds from 4 to $32 \mathrm{kHz}$. Mean \pm S.D. DPOAE thresholds were similarly elevated 7-9 days after noise exposure in NO-GC1 KO (blue diamonds), NO-GC2 KO (red triangles), and WT mice (gray squares) (WT vs. NO-GC1 KO, two-way ANOVA: genotype $P=0.3488$; WT vs. NO-GC2 KO, two-way ANOVA: genotype $P=0.8171$ ). DPOAE thresholds of sham-exposed controls remained at pre-exposure levels (shown for shamexposed WT mice, black dotted line and gray area, $n=5-6$ ears, 3 mice, repeated measures ANOVA: time $P=0.8058$, frequency $P<0.0001$, interaction $P=0.2830$ ). (B and C) Noise-induced alterations of hearing thresholds were assessed as hearing threshold loss from electrical ABR potentials in response to low tone frequency containing (click) and high tone frequency containing (noise-burst) auditory stimuli. (B) Mean \pm S.D. click-evoked ABR threshold losses for WT, NO-GC1 KO, and NO-GC2 KO mice (single mouse threshold losses as dots) 7 days after noise exposure. Both NO-GC1 KO and NO-GC2 KO mice had robust, but statistically nonsignificant, milder click-evoked ABR threshold losses than WT mice (one-way ANOVA: $P=0.0936)$. (C) Mean \pm S.D. noise-burst-evoked ABR threshold losses were robustly, but statistically nonsignificantly, weaker in NO-GC1 KO and NO-GC2 KO mice than in WT mice 7 days after noise exposure (one-way ANOVA: $P=0.1071)$. Dotted horizontal lines at $0 \mathrm{~dB}$ represent no threshold loss after noise exposure $(\mathrm{B}$ and $\mathrm{C}$ ). 
TABLE 1

Statistical comparison of distortion product otoacoustic emission thresholds between sham- and noise-exposed WT, NO-GC1 KO, and NO-GC2 KO mice

\begin{tabular}{ccccccc}
\hline \multicolumn{7}{c}{ DPOAE Thresholds (dB SPL) } \\
\hline $\mathrm{kHz}$ & $4 \mathrm{kHz}$ & $5.6 \mathrm{kHz}$ & $8 \mathrm{kHz}$ & $11.3 \mathrm{kHz}$ & $22.6 \mathrm{kHz}$ & $32 \mathrm{kHz}$ \\
\hline NO-GC WT & $>0.9999$ N.S. & $>0.9999$ N.S. & 0.1157 N.S. & $<0.0001^{* * *}$ & $0.0029^{* *}$ & $>0.9999$ N.S. \\
NO-GC1 KO & $>0.9999$ N.S. & $>0.9999 N . S$. & $>0.9999$ N.S. & $<0.0001^{* * *}$ & $0.0045^{* *}$ & $>0.9999$ N.S. \\
NO-GC2 KO & $>0.9999$ N.S. & $>0.9999 N . S$. & 0.1101 N.S. & $0.0001^{* * *}$ & $0.2016 \mathrm{~N} . S$. & $>0.9999$ N.S. \\
\hline
\end{tabular}

N.S., not significant.

Bonferroni corrected $P$ values: $* * * P<0.001$, **P $<0.01, * P<0.05$

Deletion of NO-GC1 or NO-GC2 Preserves Inner Hair Cell and Auditory Nerve Fiber Function after Noise Exposure. NO induces cGMP/cGK-dependent counteraction of ATP-induced $\mathrm{Ca}^{2+}$ signaling in isolated IHCs (Shen et al., 2003, 2005). Although noise exposure did not reveal any NO-GC isoform-dependent action on the electromechanical properties of OHCs (Fig. 2A), unexpectedly, we observed that under the same noise exposure conditions, there was a robust, yet statistically nonsignificant, difference in ABR thresholds to click and noise-burst stimuli in NO-GC isoform-specific KO and WT mice. Both NO-GC1 KO and NO-GC2 KO mice showed less severe noise-induced ABR threshold loss compared with WT mice for click (Fig. 2B, WT: $29.3 \pm 12.3, n=$ 12 ears, 6 mice; NO-GC1 KO: $20.6 \pm 5.8, n=14$ ears, 7 mice; $8.7 \mathrm{~dB}$ less threshold loss than WT; NO-GC2 KO: $19.1 \pm 4.7$, $n=12$ ears, 6 mice; $10.2 \mathrm{~dB}$ less threshold loss than WT, oneway ANOVA: $P=0.0936$ ), as well as noise-burst stimuli (Fig. 2C, WT: $38.0 \pm 12.3, n=12$ ears, 6 mice; NO-GC1 KO: $28.1 \pm$ $6.4, n=14$ ears, 7 mice; $9.9 \mathrm{~dB}$ less threshold loss than WT; NO-GC2 KO: $24.6 \pm 12.8, n=12$ ears, 6 mice; $13.5 \mathrm{~dB}$ less threshold loss than WT, one-way ANOVA: $P=0.1071$ ).

The reduced vulnerability to noise-induced hearing threshold loss in the absence of either one of the NO-GC isoforms, as detected by less severe click- and noise-burst-evoked ABR threshold loss, was not evident immediately after noise exposure. Thirty minutes after noise exposure, the noiseburst-evoked ABR thresholds between NO-GC isoformspecific KO and WT mice showed similar elevation, whereas 7 days after exposure the differences became more distinct by tendency (Table 2). Random permutation tests of noise-burstevoked ABR thresholds 7 days after noise exposure between NO-GC WT and NO-GC1 KO, as well as NO-GC WT and NO-GC2 KO mice, gave estimated $P$ values of $P=0.0076$ and $P=0.0474$ (40 repetitions of 10,000 random samples without replacement with a likelihood of the real $P$ value being $>0.05$ of less than $1 / 10^{12}$ for both comparisons; see Table 3), indicating a significantly milder noise exposure-induced hearing threshold elevation in NO-GC1 KO and NO-GC2 KO mice compared with NO-GC WT mice. This result argues against isoform-specific NO-GC deletion protecting against the initiation of IHC damage and rather suggests that recovery of IHCs from sound overexposure is NO-GC-controlled. In conclusion, as $\mathrm{OHC}$ functions were not affected after noise exposure in NO-GC isoform-specific KO mice, the altered hearing thresholds in traumatized NO-GC1 KO and NO-GC2 KO mice suggest that the NO-GC isoforms influence a key event during the recovery of the IHC synapses or of their connecting auditory fibers from noise-induced damage.

Indeed, IHC synaptic damage (synaptopathy) and auditory nerve fiber degeneration (auditory neuropathy) has been described to be independent of significant hearing threshold loss or $\mathrm{OHC}$ loss after moderate noise exposure (hidden hearing loss) (Kujawa and Liberman, 2009; Furman et al., 2013). Auditory neuropathy or IHC synaptopathy is well reflected in changes in suprathreshold ABR amplitudes or IHC ribbon numbers (Kujawa and Liberman, 2009; Jaumann et al., 2012; Chumak et al., 2016; Möhrle et al., 2016). Suprathreshold ABR wave amplitudes are expected to change proportionally with discharge rate sizes and the number of synchronously firing auditory nerve fibers (Johnson and Kiang, 1976). The auditory stimulus-evoked ABR wave I (Fig. 3) reflects the summed activity of the auditory nerve fibers (Melcher and Kiang, 1996) and is a useful functional biomarker for auditory nerve degeneration after noise exposure (Rüttiger et al., 2017).

Before noise exposure, no significant differences in auditory nerve activity occurred, as assessed by noise-burst-evoked ABR wave I amplitudes, between NO-GC1 KO or NO-GC 2 KO and WT mice (Fig. 3, A and B), NO-GC1 KO: $n=12-26$ ears, 9-13 mice, two-way ANOVA: genotype $P=0.3409$, sound level $P<0.0001$, interaction $P=0.9738$; NO-GC2 KO: $n=7-22$ ears, 7-11 mice, two-way ANOVA: genotype $P=0.9045$, sound level $P<0.0001$, interaction $P=0.9820$; WT: $n=15-22$ ears,

TABLE 2

Time course of auditory brainstem response thresholds for WT control and isoform-specific NO-GC KO mice

\begin{tabular}{lccc}
\hline \multicolumn{3}{c}{ Noise-ABR Threshold (dB SPL) } \\
& Before Noise Exposure & $\sim 30$ min After Noise Exposure & $\begin{array}{c}\text { 7 Days After Noise } \\
\text { Exposure }\end{array}$ \\
\hline NO-GC WT $n=7-12$ ears, & $8.0 \pm 4.3$ S.D. & $63.9 \pm 9.7$ S.D.** & $46.0 \pm 9.5$ S.D.** \\
4-6 mice & & $61.8 \pm 10.3$ S.D.** & $34.5 \pm 6.6$ S.D.*** $*^{* *}$ \\
NO-GC1 KO $n=7-14$ ears, 4-7 mice & $6.4 \pm 3.3$ S.D. & $59.7 \pm 14.6^{* *}$ & $33.7 \pm 12.1$ S.D.** \\
NO-GC2 KO $n=8-12$ ears, 4-6 mice & $9.2 \pm 3.4$ S.D. & $P=0.8784$ & $P=0.0663$ \\
One-way ANOVA & $P=0.4002$ & & $P$ \\
\hline
\end{tabular}

$* P<0.05$, ${ }^{*} P<0.01$, two-sided paired Student's $t$-test, comparisons between before noise exposure vs. 30 minutes after noise exposure and before noise exposure vs. 7 days after noise exposure. 
TABLE 3

Resampling of ABR thresholds for WT control and isoform-specific NO-GC KO mice

\begin{tabular}{|c|c|c|c|}
\hline \multicolumn{4}{|c|}{ Noise-ABR Threshold (dB SPL) } \\
\hline Comparison & Before Noise Exposure & $\sim 30$ min After Noise Exposure & $\begin{array}{c}7 \text { Days After } \\
\text { Noise } \\
\text { Exposure }\end{array}$ \\
\hline NO-GC WT vs. NO-GC1 KO & N.S. & N.S. & $P=0.0076^{* *}$ \\
\hline NO-GC WT vs. NO-GC2 KO & N.S. & N.S. & $P=0.0474^{*}$ \\
\hline NO-GC1 KO vs. NO-GC2 KO & N.S. & N.S. & N.S. \\
\hline
\end{tabular}

10-11 mice). In contrast, 7 days after exposure to 8 to $16 \mathrm{kHz}$ broadband noise (120 dB SPLrms for 1 hour), the ABR wave I amplitudes in both NO-GC1 KO and NO-GC2 KO mice were reduced significantly less than in age-matched WT mice (Fig. 3, D and E, WT: $n=3-12$ ears, 2-6 mice; NO-GC1 KO: $n=6-14$ ears, 4-7 mice, two-way ANOVA: genotype $P<0.0001$, sound level $P<0.0001$, interaction $P=0.1475$; NO-GC2 KO: $n=8-12$ ears, 5-6 mice, two-way ANOVA: genotype $P<0.0001$, sound level $P<0.0001$, interaction $P=0.0188$, Bonferroni's multiple comparison tests; see Table 4). In NO-GC2 KO mice, this preservation of $\mathrm{ABR}$ wave I amplitudes was more pronounced than in NO-GC1 KO mice (note the higher amplitudes in NO-GC2 KO compared with NO-GC1 KO mice in Fig. 3, E and $\mathrm{D}$, respectively, two-way ANOVA: genotype $P=0.0004$, sound level $P<0.0001$, interaction $P=0.8397$, Bonferroni's multiple comparison tests; see Table 4), indicating that the lack of NO-GC1 and, even more so, the lack of NO-GC2, significantly alleviated the long-lasting decline of summed auditory nerve responses after acoustic overstimulation.

We next sought to understand the effect of NO-GC1 and NO-GC2 on the auditory nerve at the anatomic level. In shamor noise-exposed NO-GC1 and NO-GC2 KO mice, we estimated the afferent innervation by counting the number of CtBP2/RIBEYE immunopositive dots as indicators of IHC ribbon synapses with peripheral processes of auditory neurons (Kujawa and Liberman, 2009). In line with the ABR wave I amplitudes, the IHC ribbon numbers in midbasal cochlear turns of noise-exposed NO-GC1 KO and NO-GC2 KO mice were reduced significantly less than WT mice (Fig. 3F, oneway ANOVA: $P=0.0191$; NO-GC1 KO: $12.5 \pm 2.6, n=5$ ears, 5 mice, Tukey method: $P=0.0486$; NO-GC2 KO: $13.1 \pm 2.7$, $n=5$ ears, 5 mice, Tukey method: $P=0.0241$; WT: $8.3 \pm 2.2$, $n=5$ ears, 5 mice).

In conclusion, these findings strongly suggest that the NO-GC2 and, to some extent, NO-GC1 isoform participate in the manifestation of noise-induced IHC synaptopathy and auditory nerve fiber degeneration.

NO-Mediated cGMP Responses and NO-GC Expression Identified in IHCs but not in OHCs. Previous studies using NO-GC-specific primers and RT-PCR of dissected cochlear compartments revealed a variable localization of NO-GC1 and NO-GC2 isoforms in a variety of distinct cochlear compartments, including hair cells (Seebacher et al., 1999; Heinrich et al., 2000). This scrutinizes the contribution of NO-GC1 and NO-GC2 to acoustic trauma-induced synaptopathy and auditory nerve dysfunction as a primary effect of NO-GC in the IHCs or as a secondary effect of NO-GC expression in other cochlear cells. Therefore, we performed functional measurements to directly detect NO-induced intracellular cGMP synthesis in the living cochlea in real-time using FRET microscopy and cGMP sensor mice [R26-cGi500(L1) mice] (Thunemann et al., 2013b). These cGMP sensor mice ubiquitously express the FRET-based cGMP biosensor cGi500 (cGMP-indicator with an $\mathrm{EC}_{50}$ of $500 \mathrm{nM}$ cGMP (Russwurm et al., 2007)) (Fig. 4A). Changes in cellular cGMP levels lead to conformational changes of the sensor, which then leads to changes in the CFP/YFP-fluorescence ratio $(R)$. When cochlear whole-mount preparations of 7- to 14-day-old mice $(n=5$ ears, 4 mice) were superfused with $500 \mathrm{nM}$ DEA/NO (Fig. 4B), we observed robust ratio changes in IHC but not in $\mathrm{OHC}$ regions (Fig. 4, C and D).

We further investigated NO-GC expression using NO-GC $\beta 1$-subunit-specific primers that covered a 446 -bp fragment (spanning exon 10 of NO-GC $\beta 1$ positioned at $1481-1926 \mathrm{bp}$ ) and using the membrane bound guanylate cyclase A (GC-A) as a control. From 28-day-old mice, IHCs and OHCs were dissected and mRNA isolated as described (Engel et al., 2006). As shown in an example of identical mRNA samples, nested primers amplified an expected NO-GC-specific fragment of 446-bp in probes from isolated IHCs but not from OHCs (Fig. 4E), whereas a GC-A-specific fragment was conversely amplified in probes from $\mathrm{OHCs}$ but not from IHCs (Fig. 4E).

These findings conclusively point to a hair cell-specific GC-subtype expression and function with NO-GC acting at the IHC level rather than the OHC level.

Long-Term NO-GC Stimulation Provides Evidence of NO-GC Activity at the IHC but not the OHC Level and Elucidates a Differential Effect of NO-GC Activity on Auditory Nerve Response in Young and Aged Animals. The selective expression of NO-GC in IHCs and the link to alleviation of noise-induced synaptopathy in NO-GC isoformspecific KO mice led us to investigate the influence of pharmacologic NO-GC stimulation on hearing function in vivo. To this aim, we used the nitric oxide-independent NO-GC (sGC) stimulator BAY 41-8543 (Stasch et al., 2002b). To overcome oral application two to three times a day due to the kinetic profile in rodents, chronic application with BAY 41-8543 in food pellets was chosen over a period of 25-32 days. In our hands, a stable pharmacokinetic blood level across 25 days of food pellet supply was best accomplished in the rat animal model, as previously described (Amirjanians et al., 2017). Young (2-3-month-old), middle-aged (8-11-month-old), and old (20-23-month-old) rats were either sham- or noiseexposed. Exposure to moderate noise led to a temporary click-evoked ABR threshold loss of approximately $10 \mathrm{~dB}$ in 


\section{before noise exposure}

A noise-ABR wave I

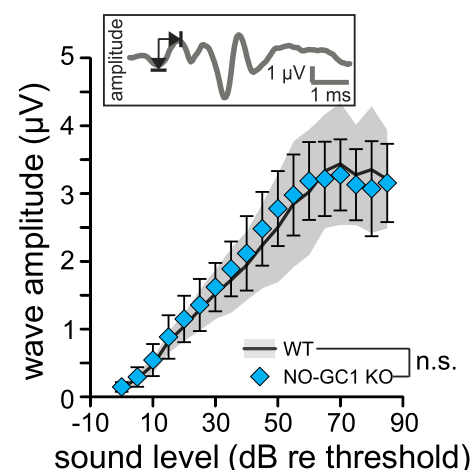

D

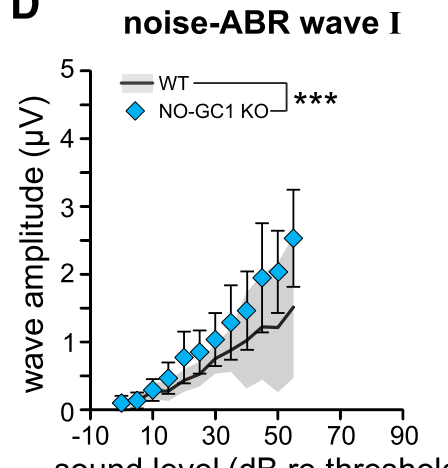

B

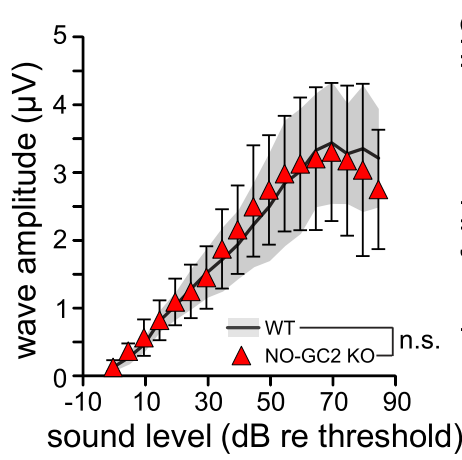

C midbasal turn

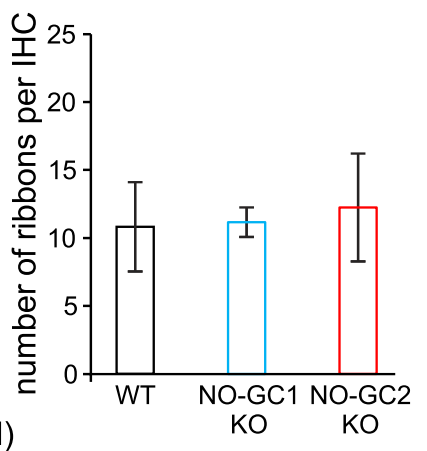

after noise exposure

E noise-ABR wave I

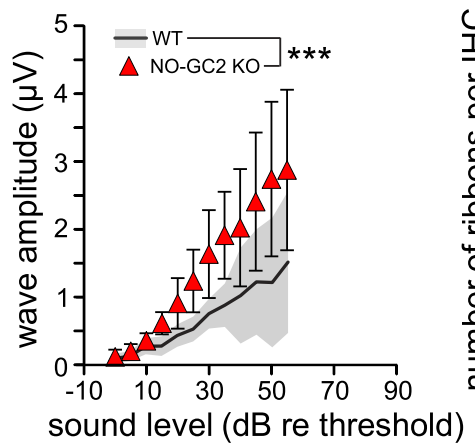

midbasal turn

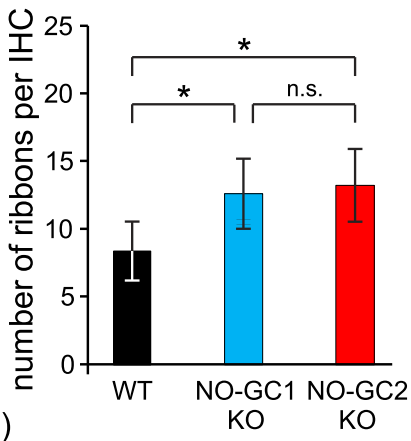

G
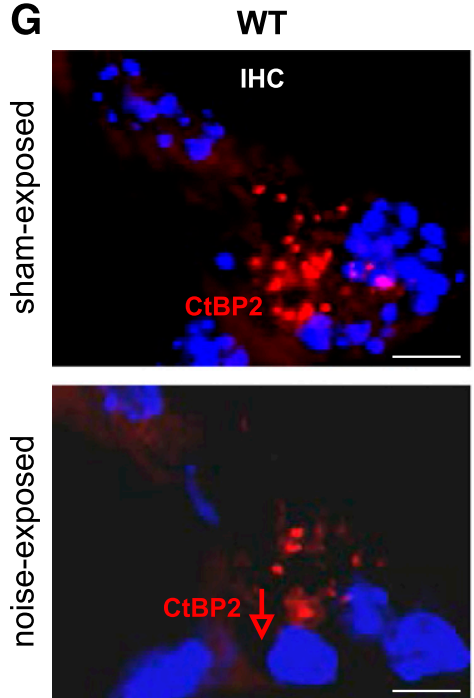

H NO-GC1 KO
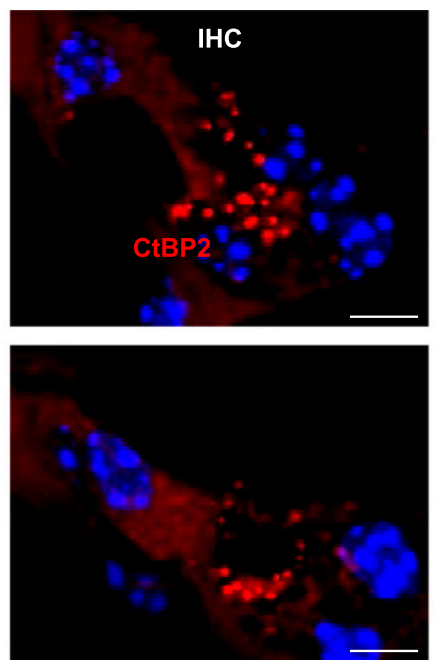

I NO-GC2 KO
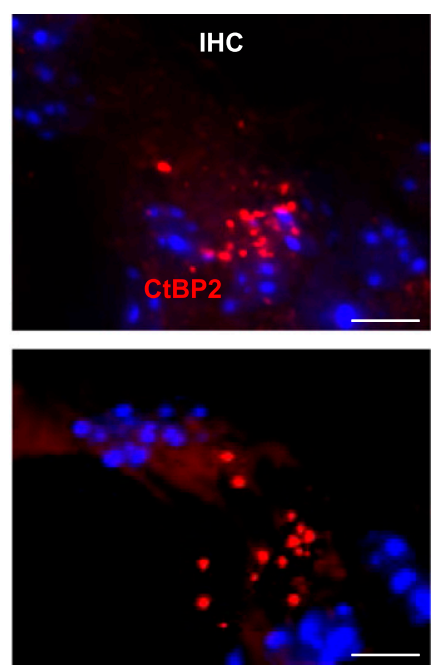

Fig. 3. Auditory nerve response amplitudes and numbers of IHC presynaptic ribbons in NO-GC WT, NO-GC1 KO, and NO-GC2 KO mice with and without noise exposure. The noise-burst stimulus-evoked ABR wave I as a measure for the summed activity of the auditory nerve fibers was assessed to investigate the effect of NO-GC1 (A) and NO-GC2 (B) deletion on auditory nerve responses in mice before noise exposure. (A) Mean \pm S.D. noise-burstevoked ABR wave I amplitude growth functions in WT (black line and gray area) and NO-GC1 KO mice (blue diamonds) were similar before noise exposure (two-way ANOVA: genotype $P=0.3409$ ). Inset: ABR wave form, indicating ABR wave I peak-to-peak amplitude $40 \mathrm{~dB}$ above the hearing threshold. (B) Mean \pm S.D. noise-burst-evoked ABR wave I amplitude growth functions in WT and NO-GC2 KO mice (red triangles) were similar before noise exposure (two-way ANOVA: genotype $P=0.9045$ ). (C and F-I) IHC ribbon synapses with afferent auditory neurons were stained by antibodies against CtBP2/RIBEYE. Immunopositive dots were counted to estimate the number of connected auditory nerve fibers per IHC. The effect of NO-GC1 and NO-GC2 deletion on IHC ribbon counts was analyzed in sham- (C and G-I, upper panel) and noise-exposed (F and G-I, lower panel) mice. (C) Mean \pm S.D. ribbon numbers of IHCs in midbasal cochlear turns were not significantly different in NO-GC1 KO (blue bar, $11.2 \pm 1.1, n=5$ ears, 5 mice) and NO-GC2 KO mice (red bar, $12.3 \pm 4.0, n=4$ ears, 4 mice) compared with WT mice without noise exposure (white bar, $10.8 \pm 3.3, n=5$ ears, 5 mice, one-way ANOVA: $P=0.7638$ ). (D and E) The stimulus-evoked ABR wave I was assessed to investigate the effect of noise exposure on the summed activity of the 
young (13.5 $\pm 4.4, n=22$ ears, 11 rats $)$, middle-aged $(13.0 \pm$ $5.2, n=36$ ears, 18 rats $)$, and old rats $(9.1 \pm 5.4, n=12$ ears, 6 rats). Starting on the third day after the exposure, subgroups of rats were treated with the NO-GC stimulating substance BAY 41-8543 over a period of 25-32 days; 28 days after exposure, ABR thresholds recovered to control levels in both noise-exposed groups with or without NO-GC stimulator treatment (as shown for middle-aged animals in Fig. 5A, sham-exposed without stimulator: $n=18$ ears, 9 rats; noiseexposed without stimulator: $n=18$ ears, 9 rats; sham-exposed with stimulator: $n=18$ ears, 9 rats; noise-exposed with stimulator: $n=18$ ears, 9 rats, one-way ANOVA: $P=0.8766$ ). Similar to ABR thresholds, DPOAE thresholds across stimulus frequencies of $\mathrm{f2}=4-32 \mathrm{kHz}$ were not elevated in noise-exposed rats compared with sham-exposed controls independent of NO-GC stimulator treatment (as shown for middle-aged animals in Fig. 5B, sham-exposed without stimulator: $n=18$ ears, 9 rats; sham-exposed with stimulator: $n=16-18$ ears, 9 rats; noise-exposed without stimulator: $n=18$ ears, 9 rats; noiseexposed with stimulator: $n=17-18$ ears, 9 rats, two-way ANOVA; see Table 5).

Long-term treatment of young, middle-aged, or old sham- or noise-exposed animals with the NO-independent NO-GC stimulator BAY 41-8543 for approximately 4 weeks had no impact on ABR thresholds or electromechanical properties of OHCs. This conclusion supports the notion that the activation of NO-GC does not influence OHC function or hearing thresholds, either before or after noise exposure.

To further investigate the role of NO-GC in auditory-nerve degeneration, changes in suprathreshold ABR wave I amplitudes were analyzed at stimulus levels between 40 and $60 \mathrm{~dB}$ above threshold. The amplitude differences between shamexposed controls with vs. without stimulator and between noise-exposed rats with vs. without stimulator are summarized in Fig. 5C as the "treatment benefit" for young, middle-aged, and old rats. ABR wave I amplitudes were not different between sham-exposed rats with or without NO-GC stimulator treatment in all age groups (Fig. 5C, sham-exposed with vs. without stimulator; young sham-exposed with stimulator: $n=$ 12 ears, 6 rats; young sham-exposed without stimulator: $n=$ 9 ears, 5 rats, two-sided Student's $t$-test: $P=0.5396$; middleaged sham-exposed with stimulator: $n=18$ ears, 9 rats; middle-aged sham-exposed without stimulator: $n=18$ ears, 9 rats, two-sided Student's $t$ test: $P=0.8242$; old shamexposed with stimulator: $n=6$ ears, 3 rats; old sham-exposed without stimulator: $n=6$ ears, 3 rats, two-sided Student's $t$-test: $P=0.9881)$. Noise-exposed young rats with NO-GC stimulator treatment, however, showed a significant gain of ABR wave I amplitude compared to noise-exposed young rats without NO-GC stimulator treatment (Fig. 5C, noise-exposed with vs. without stimulator; young noise-exposed with stimulator: $n=12$ ears, 6 rats; young noise-exposed without stimulator: $n=10$ ears, 5 rats, two-sided Student's $t$-test: $P=$ 0.0279), indicating that the in vivo application of NO-GC stimulator in young animals preserves ABR wave I amplitude after noise exposure. With NO-GC stimulator treatment, however, there was a significant loss of ABR wave I amplitude in noise-exposed middle-aged rats (Fig. 5C, noise-exposed with vs. without stimulator; middle-aged noise-exposed with stimulator: $n=18$ ears, 9 rats; middle-aged noise-exposed without stimulator: $n=18$ ears, 9 rats, two-sided Student's $t$-test: $P=0.0094)$ and, although not statistically significant, in noise-exposed old rats (Fig. 5C, noise-exposed with vs. without stimulator; old noise-exposed with stimulator: $n=$ 6 ears, 3 rats; old noise-exposed without stimulator: $n=6$ ears, 3 rats, two-sided Student's $t$-test: $P=0.2255$ ) in comparison with noise-exposed rats without stimulator.

These results indicate that during the last two-thirds of life, in rats, pharmacologic long-term stimulation of the NO-GC/cGMP pathway, starting on the third day after exposure for approximately 4 weeks, exacerbates the loss of auditory nerve response after noise exposure, whereas the same treatment in young animals counteracts the loss of auditory nerve response after noise exposure.

In conclusion, this study demonstrates that: 1) NO-GC1 and NO-GC2 do not influence basic hearing function; 2) neither NO-GC1 nor NO-GC2 isoform deletion nor long-term stimulation of NO-GC influences $\mathrm{OHC}$ function before or after noise exposure; 3) NO-GC expression and NO-induced cGMP synthesis were not detected in OHCs; 4) NO-GC expression and NO-induced cGMP synthesis were, however, detected in IHCs; and 5) the long-term in vivo NO-GC stimulation, starting on the third day after noise injury, preserved auditory nerve responses in young animals; the same treatment after noise injury reversed this beneficial effect in aged animals. The NO-GC signaling cascade may therefore participate in the loss of the IHC synapses and contribute to auditory nerve degeneration during traumatic conditions with progressing age.

\section{Discussion}

The current study provides the first evidence for a hair cellspecific role of NO-GC1 and NO-GC2 isoforms; these are expressed and act at the IHC, but not OHC level of the mammalian cochlea. Moreover, we provide evidence that NO-GC especially affects the integrity of the functional connection between auditory nerve fibers and IHCs in stressful situations (e.g., acoustic overexposure). Whereas the less deteriorated auditory nerve response after acoustic overexposure in NO-GC1 and NO-GC2 KO mice suggested that NO-GC stimulation negatively influences the auditory nerve response, the analysis of long-term effects of NO-GC stimulation provides a more complex picture; that is to say, NO-GC stimulation for longer periods in young animals attenuated

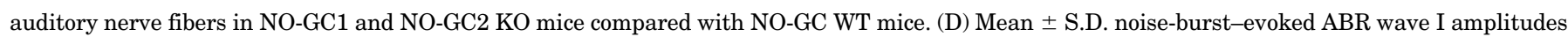

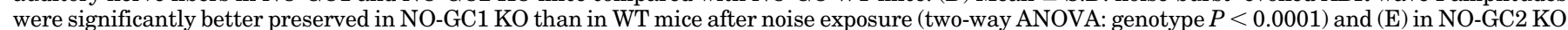

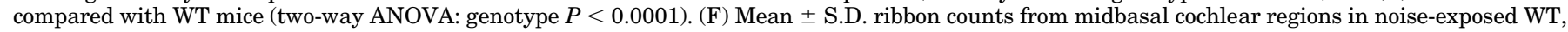

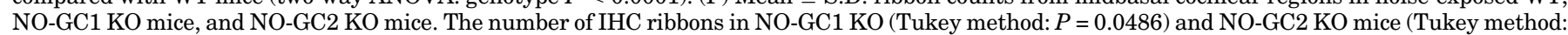

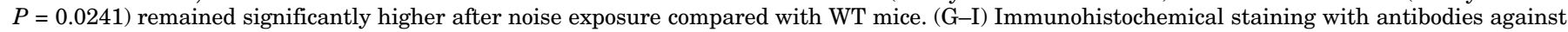

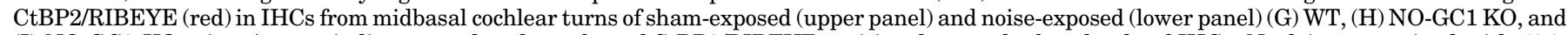

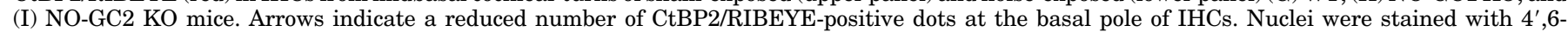
diamidin-2-phenylindol (DAPI, blue). Scale bars, $5 \mu \mathrm{m}$. $* P \leq 0.05$; *** $P \leq 0.001$; n.s., not significant.
} 
auditory nerve degeneration after acoustic overexposure, whereas the same treatment significantly worsened the auditory nerve response in aged animals. We discuss the findings through the framework that in young, but not in old, animals, NO-GC can promote a prosurvival stress resistance in IHCs.

No Crucial Role of NO-GC1 and NO-GC2 for Basic Hearing or OHC Function. The deletion of NO-GC1 and NO-GC2 did not affect normal hearing function or OHC function, nor did it influence hearing threshold shortly after acoustic overexposure. Under basic conditions, the hearing thresholds for ABRs evoked by click and noise-burst stimuli were not significantly different in NO-GC isoform-specific KO and WT mice. Also, the $\mathrm{OHC}$ electromechanical properties that mainly determine hearing sensitivity (Avan et al., 2001; El-Badry and McFadden, 2007; Dalhoff et al., 2010) were normal when NO-GC isoforms were deleted. Even after noise exposure, the elevation of the DPOAE thresholds did not differ in NO-GC1 KO, NO-GC2 KO, and WT control animals. This finding is striking considering that $\mathrm{NO}$ in OHCs has shown elevation in response to ATP-gated P2X receptor activation or hyposmotic conditioning of isolated OHCs (Shen et al., 2006; Takeda-Nakazawa et al., 2007). A normal hearing threshold in NO-GC1 or NO-GC2 KO mice might be due to a redundant capacity of the individual NO-GC1 and NO-GC2 isoforms as can be concluded from the nearly normal basic body functions observed in both NO-GC1 and NO-GC2 KO mice (Neitz et al., $2011,2014)$. These normal body functions of NO-GC isoformspecific KO mice are in contrast to the phenotype of global NO-GC KO mice, which show severe problems in smooth muscle relaxation and platelet inhibition, with subsequent elevated blood pressure and fatal gastrointestinal obstruction, a phenotype that typically leads to a lethality within the first postnatal weeks (Friebe et al., 2007). As for the finding that chronic intake of NO-GC stimulator BAY 41-8543 via enriched food over 25-32 days did not affect the hearing thresholds of young, middle-aged, or old rats, with and without acoustic overexposure, argues against a redundant NO-GC1 or NO-GC2 isoform activity in OHCs. Thus, the NO production in OHCs, previously observed to counteract $\mathrm{Ca}^{2+}$ signaling after induced hyposmotic swelling of OHCs (Shen et al., 2006; Takeda-Nakazawa et al., 2007), may be considered in the context of a nonphysiologic response of hair cells isolated from their surrounding tissue. Further support for NO-GC not being a relevant factor in OHCs came from the observation that NO-GC-specific mRNA was not found in acutely isolated OHCs, although the cGMP-generating membrane-bound guanylate cyclase A was identified in identical mRNA samples (Fig. 4E). Moreover, the NO donor DEA/NO (Thunemann et al., 2013b) could not elevate the OHC cGMP level in cGMP sensor mice [R26-cGi500(L1) mice], as investigated with FRET microscopy in ex vivo cochlea preparations.

In conclusion, we argue against NO-GC1 or NO-GC2 as relevant active components in OHCs before or after noise exposure.

Role of NO-GC1 and NO-GC2 in Noise-Induced IHC Synaptopathy. We demonstrate that NO-GC1 KO and NO-GC2 KO mice have better preserved auditory fiber responses after noise exposure. A significantly weaker IHC ribbon loss and a less pronounced ABR wave I amplitude reduction were observed in KO mice compared with WT control mice. This finding indicates a deteriorating effect of NO-GC on auditory nerve preservation during acoustic overexposure. 

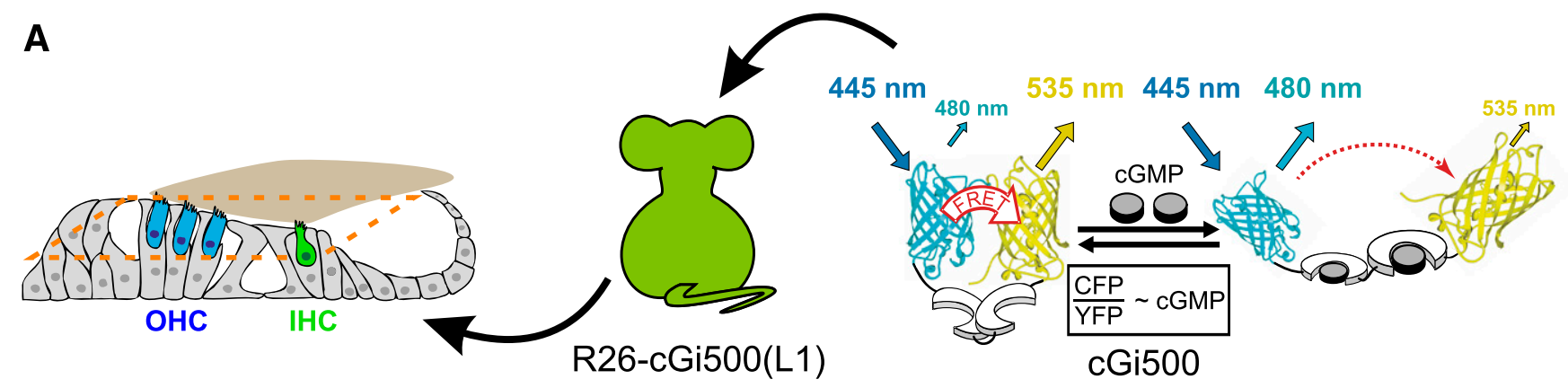

B

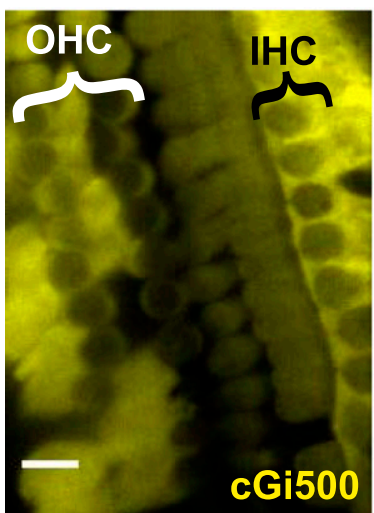

C

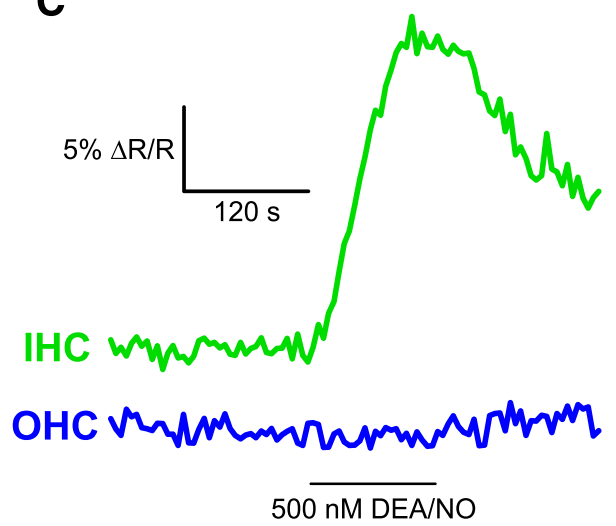

D

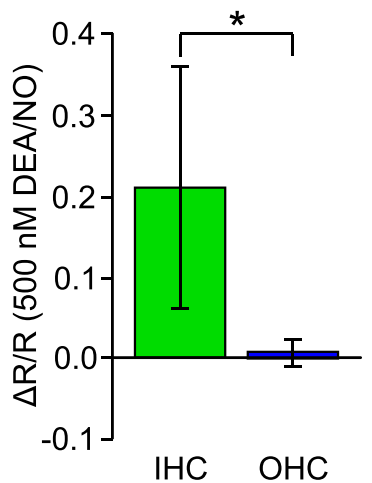

E

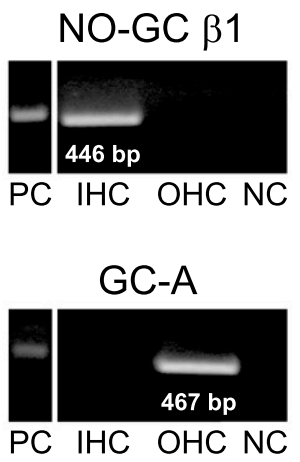

Fig. 4. NO-induced changes in cGMP levels by FRET measurements and NO-GC expression in cochlear hair cells. (A) NO-induced changes in cellular cGMP levels were assessed by the cGMP-reflecting CFP/YFP-ratio $(R)$ in cochlear whole-mount preparations from R26-cGi500(L1) mice that express the FRET-based cGMP biosensor cGi500. (B) Representative fluorescence image showing the sensor expression in cochlear whole-mounts (scale bar, $10 \mu \mathrm{m}$ ). The visible differences in absolute fluorescence intensity are due to differences in sensor expression and do not reflect different cGMP levels. (C) Representative ratio $(R)$-traces, reflecting the increase in cellular cGMP-levels in either IHC (green) or OHC regions (blue) upon application of $500 \mathrm{nM}$ DEA/NO. The increase in cGMP reversed when DEA/NO was washed out. (D) The maximum amplitude of DEA/NO-induced ratio changes was quantified and averaged for IHC (green) and OHC regions (blue) of five isolated cochleae from four mice from three different litters (mean \pm S.D., two-sided Student's $t$-test: $P=0.036$ ). (E) RT-PCR of WT IHC and OHC cDNA showing a fragment of the NO-GC $\beta 1$-subunit at 446-bp (upper panel) and of the GC-A at $467-\mathrm{bp}$ (lower panel) from the same gel. NO-GC $\beta 1$-subunit was expressed only in IHCs, not in OHCs. Conversely, GC-A expression was found only in OHCs, but not IHCs. All lanes are from the same gel; lanes between PC and IHC samples were removed as they contained results not relevant for this experiment. NC, negative control; PC, positive control (heart). $* P \leq 0.05$

When NO-GC stimulator BAY 41-8543 (Stasch and Evgenov, 2013) was applied for 25-32 days after sound exposure in middle-aged and old rats, we also noted that the IHC synaptopathy was increased compared with untreated animals. In contrast, a long-term intake of NO-GC stimulator after acoustic overexposure significantly attenuated the IHC synaptopathy in young animals (Fig. 5C).

These findings require careful interpretation, and more detailed studies need to be conducted to further substantiate these claims. In the current experiments, given that only one dose of BAY 41-8543 was applied, the kinetic profiles of BAY 41-8543 might be age-dependent as well. Similar to the findings in NO-GC isoform-specific $\mathrm{KO}$ mice that suggest that the activity of NO-GC1 and NO-GC2 is detrimental to IHC synapse integrity after acoustic overexposure by an elevated susceptibility to excitotoxicity, the aging process might lead to an elevated susceptibility to excitotoxicity as well. In contrast, a reduced susceptibility to noise-induced excitotoxicity is observed in young animals with NO-GC stimulator treatment, possibly through the promotion of a prosurvival activity downstream of NO-GC. Indeed, treatment with the cGMPhydrolyzing phosphodiesterase 5 inhibitor vardenafil induces activity of the prosurvival poly (ADP-ribose) (PAR) polymerase (PARP) in the cochlea and cGKI-deficient mice showed reduced levels of PAR polymers (Jaumann et al., 2012). PAR has been shown to enhance prosurvival activity of peroxisome proliferator-activated receptor (PPAR) (Erener et al., 2012; Lehmann et al., 2015) that in turn regulates genes promoting lipid oxidation and metabolism of lipoproteins, such as main apo-lipoprotein of high density, ApoA-1. Through these activities, PPAR antagonizes the metabolic syndrome and aging in general (Schiff et al., 2012) and increases stress resistance in various body functions (Moskalev et al., 2014). It is important to note that the signaling cascades that activate PARP must be allocated to the group of genes that, according to the antagonistic pleiotropy theory, elevates stress resistance early in life but acts detrimentally in older organisms (Moskalev et al., 2014). In line with the possibility that NO-GC activates prosurvival cascades in young but not in aged animals, prosurvival PARP activity is observed downstream of cGMPcGKI signaling in the cochlea of young animals (Jaumann et al., 2012), as it is in neuronal cells (Kim et al., 1999), whereas a prosurvival PARP activity downstream of NO-GC was suggested to be lost in various species over age (Grube and Bürkle, 1992).

Regarding such a concept, prosurvival genes may promote the resistance to stress preferentially in early life, enabling, for example, the counteraction of excitotoxic events mediated by glutamate-activated N-methyl-D-aspartate (NMDA) receptors that in the cochlea have been described to promote 

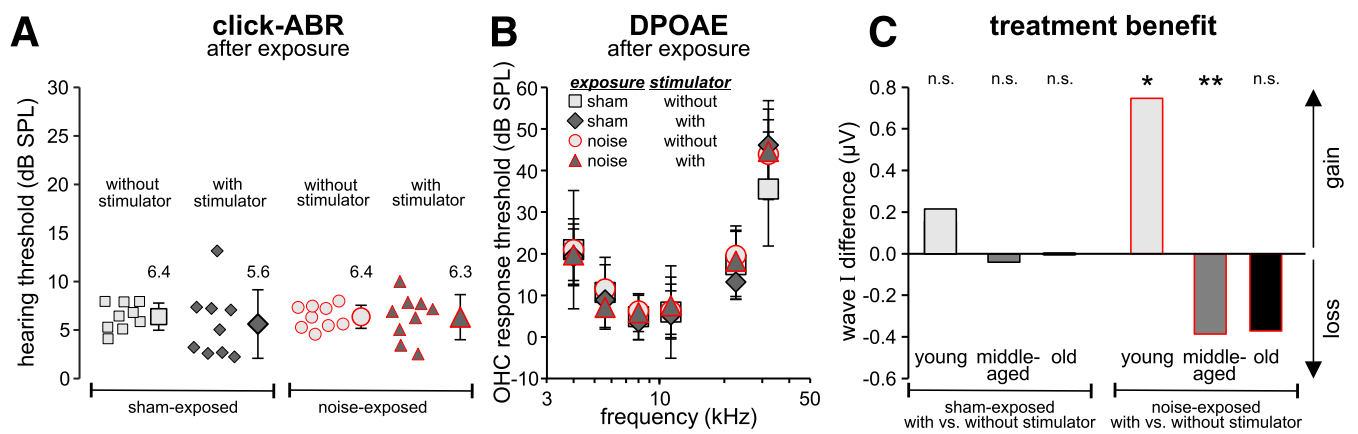

Fig. 5. Effects of NO-GC stimulator treatment after noise exposure on ABR thresholds, OHC function, and the summed auditory nerve response in young, middle-aged, and old rats. ABR potential thresholds in response to lower frequency click stimuli (A), thresholds of DPOAEs in response to pure tone sounds from 4 to $32 \mathrm{kHz}$ (B), and the "treatment benefit" of the NO-GC stimulator BAY 41-8543 on the click-evoked ABR wave I amplitude (difference between the amplitude before and after the sham or noise exposure) $(C)$ were measured in rats that were either sham-or noise-exposed, with and without NO-GC stimulator treatment, to investigate the effects of NO-GC stimulation on the recovery of the hearing thresholds, OHC function, and auditory nerve responses after noise exposure. (A) Mean \pm S.D. click-evoked ABR thresholds 4 weeks after exposure in middle-aged, sham-exposed, pharmacologically untreated rats (light gray square, single rat thresholds as small squares); sham-exposed, NO-GC stimulator-treated rats (dark gray diamond, single rat thresholds as small diamonds); noise-exposed, pharmacologically untreated rats (light gray circle, single rat thresholds as small circles); noise-exposed, NO-GC stimulator-treated rats (dark gray triangle, single rat thresholds as small triangles) were not significantly different (oneway ANOVA: $P=0.8766$ ). (B) Mean \pm S.D. DPOAE thresholds were not significantly different 4 weeks after the exposure in middle-aged, sham-exposed rats with or without NO-GC stimulator and noise-exposed rats with or without NO-GC stimulator (two-way ANOVA; see Table 5). (C) Sham-exposed young (light gray bar), middle-aged (gray bar), and old rats (dark gray bar) treated with the NO-GC stimulator did not show differences in ABR wave I amplitudes at 40-60 dB above threshold compared with sham-exposed rats without the stimulator of the respective age group (sham-exposed with vs. without simulator, young, two-sided Student's $t$-test: $P=0.5396$; middle-aged, two-sided Student's $t$-test: $P=0.8242$; old, two-sided Student's $t$-test: $P=0.9881$ ). Middle-aged (two-sided Student's $t$-test: $P=0.0094$ ) and old, noise-exposed rats (two-sided Student's $t$-test: $P=0.2255$ ) treated with the NO-GC stimulator lost more ABR wave I amplitude than noise-exposed rats without the stimulator (noise-exposed with vs. without simulator). Only young, noise-exposed rats treated with the NO-GC stimulator showed a gain in ABR wave I amplitudes compared with noise-exposed young rats without the stimulator (two-sided Student's $t$-test: $P=0.0279$ ). Asterisks denote statistically significant differences between equally exposed rats treated with or without the NO-GC stimulator for all three age groups.

afferent neurodegeneration after noise trauma or cochlear injury (Puel, 1995; d'Aldin et al., 1997; Ruel et al., 2000, 2008). While not shown for the auditory system, in aged hippocampal neurons, susceptibility to excitotoxicity has been shown to increase as a result of age-related enhanced susceptibility to NMDA-mediated excitotoxicity (Porter et al., 1997; Brewer et al., 2007; Calvo et al., 2015), a feature possibly linked to the loss of prosurvival activity over age (Moskalev et al., 2014). If the observed increased vulnerability of auditory fiber responses to NO-GC stimulation over age, as observed in the present study, is due to a decline in prosurvival activities, such as PARP, needs to be clarified in future studies. It is important to note that NO-GC can indirectly promote NMDA receptor activity. Accordingly, NO-GC1 enhances presynaptic glutamate release via hyperpolarization-activated cyclic nucleotide-gated cation (HCN) blocker-sensitive channels in hippocampal neurons (Neitz et al., 2011), whereas NO-GC2-induced elevation of cGMP in postsynapses shifts the voltage dependence of $\mathrm{HCN}$ channels to more depolarized values. Thereby, NO-GC1 and NO-GC2 indirectly enhance the hyperpolarization-activated cation inward current $I_{\mathrm{h}}$ generated by HCN channels, which contributes to the membrane depolarization required for NMDA receptor activation (Neitz et al., 2014; Koesling et al., 2016). HCN channel activities also play a role in hair cell function and auditory fiber excitability (Horwitz et al., 2010; Yi et al., 2010; Ramakrishnan et al., 2012; Kim and Holt, 2013; KoppScheinpflug et al., 2015), although the role of HCN current during noise trauma has not yet been investigated. Unlike in the hippocampus, the findings of the present study strongly support the notion that NO-GC1 or NO-GC2 in the cochlea may not induce long-term potentiation but, as discussed already herein, contribute to NMDA receptor-mediated excitotoxicity in auditory fibers particularly in the aging cochlea, when possibly NO-GC-induced prosurvival activity has declined. In young animals, NO-GC may counteract the progression of acoustic stress-induced injury through elevation of, for example, prosurvival PARP activity (Jaumann et al., 2012).

It remains elusive whether the action of NO-GC in cochlear synaptopathy is restricted to NO-GC activity in IHCs. Also, nonauditory cells could be involved in the NO-GC-influenced recovery of the IHC synapses and auditory fibers from noiseinduced damage. Noise exposure can induce cochlear inflammatory responses like generation of proinflammatory mediators and recruitment of inflammatory cells (Yang et al., 2015; Tan et al., 2016), which might cause hair cell damage (Tabuchi and Hara, 2012). Anti-inflammatory therapies have been proposed as treatment strategy for acute sensory-neural hearing loss (Wakabayashi et al., 2010). How the NO/NO-GC/cGMP cascade interacts with the cellular immune response in the inner ear is unknown. In the brain, neurite outgrowth after ischemia (Moretti et al., 2016) and

\section{TABLE 5}

Statistical comparison of distortion product otoacoustic emission thresholds 4 weeks after exposure in middle-aged rats

$P$ values reported for main effect of treatment.

\begin{tabular}{lc}
\hline \multicolumn{1}{c}{ Comparison } & $\begin{array}{c}\text { Two-Way } \\
\text { ANOVA }\end{array}$ \\
\hline $\begin{array}{l}\text { Sham-exposed without } \text { stimulator vs. sham-exposed } \\
\text { with stimulator }\end{array}$ & $P=0.9372$ \\
$\begin{array}{l}\text { Sham-exposed without } \text { stimulator vs. noise-exposed } \\
\text { without } \text { stimulator }\end{array}$ & $P=0.2158$ \\
$\begin{array}{l}\text { Sham-exposed with } \text { stimulator vs. noise-exposed } \\
\text { with stimulator }\end{array}$ & $P=0.3943$ \\
$\begin{array}{l}\text { Noise-exposed without } \text { stimulator vs. noise-exposed } \\
\text { with stimulator }\end{array}$ & $P=0.4782$ \\
$\begin{array}{l}\text { Sham-exposed without } \text { stimulator vs. noise-exposed } \\
\text { with stimulator }\end{array}$ & $P=0.4823$ \\
$\begin{array}{c}\text { Sham-exposed with } \text { stimulator vs. noise-exposed } \\
\text { without } \text { stimulator }\end{array}$ & $P=0.1169$ \\
\hline
\end{tabular}


microglia regulation in acute inflammation (Scheiblich and Bicker, 2016) are NO- and cGMP-dependent. cGMP-elevating drugs play an important role in cell growth and survival and most likely interfere with cancer pathogenesis (Peak et al., 2016). Whereas no altered inflammatory responses in cardiac tissue were found in NO-GC1 KO mice (Buys et al., 2009), the NO-GC stimulator BAY 41-8543 has the potential to prevent inflammation of cardiac tissue in a rat model of hypertensioninduced heart failure (Haase et al., 2015). Local application of NO-GC stimulator to the cochlea or the generation of IHCspecific NO-GC KO mice may allow differentiation IHCspecific and systemic NO-GC-mediated auditory effects in future studies. Although the mode of action is still speculative, the prevention of auditory nerve fiber degeneration (hidden hearing loss) caused by noise and aging should include NO-GC stimulation as a treatment strategy within a therapeutic window when prosurvival pathways can still elevate stress resistance.

\section{Acknowledgments}

The authors thank Michael Paolillo for offering language advice.

\section{Authorship Contributions}

Participated in research design: Möhrle, Reimann, Wolters, Mergia, Ruth, Friebe, Feil, Koesling, Knipper, Rüttiger.

Conducted experiments: Möhrle, Reimann, Wolters, Varakina,

Eichert, Geisler, Rüttiger.

Contributed new reagents or analytic tools: Sandner.

Performed data analysis: Möhrle, Reimann, Wolter, Wolters, Varakina, Eichert, Geisler, Knipper, Rüttiger.

Wrote or contributed to the writing of the manuscript: Möhrle, Reimann, Wolters, Geisler, Sandner, Ruth, Friebe, Feil, Zimmermann, Koesling, Knipper, Rüttiger.

\section{References}

Amirjanians M, Egemnazarov B, Sydykov A, Kojonazarov B, Brandes R, Luitel H, Pradhan K, Stasch JP, Redlich G, Weissmann N, et al. (2017) Chronic intratracheal application of the soluble guanylyl cyclase stimulator BAY 41-8543 ameliorates experimental pulmonary hypertension. Oncotarget 8:29613-29624.

Avan P, Bonfils P, and Mom T (2001) Correlations among distortion product otoacoustic emissions, thresholds and sensory cell impairments. Noise Health 3:1-18.

Bharadwaj HM, Verhulst S, Shaheen L, Liberman MC, and Shinn-Cunningham BG (2014) Cochlear neuropathy and the coding of supra-threshold sound. Front Syst Neurosci 8:26.

Bohne BA and Harding GW (2000) Degeneration in the cochlea after noise damage: primary versus secondary events. Am J Otol 21:505-509.

Bramhall N, Ong B, Ko J, and Parker M (2015) Speech perception ability in noise is correlated with auditory brainstem response wave I amplitude. J Am Acad Audiol 26:509-517.

Brewer LD, Thibault O, Staton J, Thibault V, Rogers JT, Garcia-Ramos G, Kraner S, Landfield PW, and Porter NM (2007) Increased vulnerability of hippocampal neurons with age in culture: temporal association with increases in NMDA receptor current, NR2A subunit expression and recruitment of L-type calcium channels. Brain Res 1151:20-31.

Buran BN, Strenzke N, Neef A, Gundelfinger ED, Moser T, and Liberman MC (2010) Onset coding is degraded in auditory nerve fibers from mutant mice lacking synaptic ribbons. J Neurosci 30:7587-7597.

Burkard RF and Don M (2007) The auditory brainstem response, in Auditory Evoked Potentials: Basic Principles and Clinical Application (Burkard RF, Don M, and Eggemond JJ, eds) pp 229-250, Lippincott Williams \& Wilkins, Baltimore.

Buys ES, Cauwels A, Raher MJ, Passeri JJ, Hobai I, Cawley SM, Rauwerdink KM, Thibault H, Sips PY, Thoonen R, et al. (2009) $\operatorname{sGC}(\alpha)_{1}(\beta)_{1}$ attenuates cardiac dysfunction and mortality in murine inflammatory shock models. Am J Physiol Heart Circ Physiol 297:H654-H663.

Calvo M, Sanz-Blasco S, Caballero E, Villalobos C, and Núñez L (2015) Susceptibility to excitotoxicity in aged hippocampal cultures and neuroprotection by nonsteroidal anti-inflammatory drugs: role of mitochondrial calcium. $J$ Neurochem 132:403-417.

Chumak T, Rüttiger L, Lee SC, Campanelli D, Zuccotti A, Singer W, Popeláŕ J, Gutsche K, Geisler HS, Schraven SP, et al. (2016) BDNF in lower brain parts modifies auditory fiber activity to gain fidelity but increases the risk for generation of central noise after injury. Mol Neurobiol 53:5607-5627.

d'Aldin CG, Ruel J, Assié R, Pujol R, and Puel JL (1997) Implication of NMDA type glutamate receptors in neural regeneration and neoformation of synapses after excitotoxic injury in the guinea pig cochlea. Int $J$ Dev Neurosci 15:619-629.

Dalhoff E, Vetesník A, Turcanu D, and Gummer AW (2010) Sound and velocity DPOAEs: technology, methodology and perspectives. HNO 58:543-555.
Duncker SV, Franz C, Kuhn S, Schulte U, Campanelli D, Brandt N, Hirt B, Fakler B, Blin N, Ruth P, et al. (2013) Otoferlin couples to clathrin-mediated endocytosis in mature cochlear inner hair cells. J Neurosci 33:9508-9519.

El-Badry MM and McFadden SL (2007) Electrophysiological correlates of progressive sensorineural pathology in carboplatin-treated chinchillas. Brain Res 1134:122-130.

Engel J, Braig C, Rüttiger L, Kuhn S, Zimmermann U, Blin N, Sausbier M, Kalbacher $\mathrm{H}$, Münkner S, Rohbock K, et al. (2006) Two classes of outer hair cells along the tonotopic axis of the cochlea. Neuroscience 143:837-849.

Erener S, Mirsaidi A, Hesse M, Tiaden AN, Ellingsgaard H, Kostadinova R, Donath MY, Richards PJ, and Hottiger MO (2012) ARTD1 deletion causes increased hepatic lipid accumulation in mice fed a high-fat diet and impairs adipocyte function and differentiation. FASEB $J$ 26:2631-2638.

Evgenov OV, Pacher P, Schmidt PM, Haskó G, Schmidt HH, and Stasch JP (2006) NO-independent stimulators and activators of soluble guanylate cyclase: discovery and therapeutic potential. Nat Rev Drug Discov 5:755-768.

Friebe A, Mergia E, Dangel O, Lange A, and Koesling D (2007) Fatal gastrointestinal obstruction and hypertension in mice lacking nitric oxide-sensitive guanylyl cyclase. Proc Natl Acad Sci USA 104:7699-7704.

Füllgrabe C, Moore BC, and Stone MA (2015) Age-group differences in speech identification despite matched audiometrically normal hearing: contributions from auditory temporal processing and cognition. Front Aging Neurosci 6:347.

Furman AC, Kujawa SG, and Liberman MC (2013) Noise-induced cochlear neuropathy is selective for fibers with low spontaneous rates. $J$ Neurophysiol 110:577-586.

Groneberg D, Voussen B, and Friebe A (2016) Integrative control of gastrointestinal motility by nitric oxide. Curr Med Chem 23:2715-2735

Grube K and Bürkle A (1992) Poly(ADP-ribose) polymerase activity in mononuclear leukocytes of 13 mammalian species correlates with species-specific life span. Proc Natl Acad Sci USA 89:11759-11763.

Haase N, Wilck N, Marko L, Balogh A, Heuser A, Brockschnieder D, Kretschmer A, Stasch JP, Müller N, and Dechend R (2015) The sGC stimulator BAY 41-8543 in a rat model of hypertension-induced heart failure. BMC Pharmacol Toxicol 16 (Suppl 1):A57.

Harding GW, Bohne BA, and Ahmad M (2002) DPOAE level shifts and ABR threshold shifts compared to detailed analysis of histopathological damage from noise. Hear Res 174:158-171.

Heinrich U, Maurer J, Koesling D, Mann W, and Förstermann U (2000) Immunoelectron microscopic localization of the $\alpha\left(_{1}\right)$ and $\beta\left({ }_{1}\right)$-subunits of soluble guanylyl cyclase in the guinea pig organ of corti. Brain Res 885:6-13.

Horwitz GC, Lelli A, Géléoc GS, and Holt JR (2010) HCN channels are not required for mechanotransduction in sensory hair cells of the mouse inner ear. PLoS One 5 : e8627.

Jaumann M, Dettling J, Gubelt M, Zimmermann U, Gerling A, Paquet-Durand F, Feil S, Wolpert S, Franz C, Varakina K, et al. (2012) cGMP-Prkg1 signaling and Pde5 inhibition shelter cochlear hair cells and hearing function. Nat Med 18: 252-259.

Johnson DH and Kiang NY (1976) Analysis of discharges recorded simultaneously from pairs of auditory nerve fibers. Biophys $J$ 16:719-734

Kharkovets T, Dedek K, Maier H, Schweizer M, Khimich D, Nouvian R, Vardanyan $\mathrm{V}$, Leuwer R, Moser T, and Jentsch TJ (2006) Mice with altered KCNQ4 K ${ }^{+}$ channels implicate sensory outer hair cells in human progressive deafness. $E M B O$ $J$ 25:642-652.

Kim YH and Holt JR (2013) Functional contributions of HCN channels in the primary auditory neurons of the mouse inner ear. J Gen Physiol 142:207-223.

Kim YM, Chung HT, Kim SS, Han JA, Yoo YM, Kim KM, Lee GH, Yun HY, Green A Li J, et al. (1999) Nitric oxide protects PC12 cells from serum deprivation-induced apoptosis by cGMP-dependent inhibition of caspase signaling. J Neurosci 19:6740-6747. Knipper M, Gestwa L, Ten Cate WJ, Lautermann J, Brugger H, Maier H, Zimmermann U, Rohbock K, Köpschall I, Wiechers B, et al. (1999) Distinct thyroid hormone-dependent expression of TrKB and $\mathrm{p} 75^{\mathrm{NGFR}}$ in nonneuronal cells during the critical TH-dependent period of the cochlea. J Neurobiol 38:338-356.

Knipper M, Zinn C, Maier H, Praetorius M, Rohbock K, Köpschall I, and Zimmermann U (2000) Thyroid hormone deficiency before the onset of hearing causes irreversible damage to peripheral and central auditory systems. J Neurophysiol 83:3101-3112.

Knirsch M, Brandt N, Braig C, Kuhn S, Hirt B, Münkner S, Knipper M, and Engel J (2007) Persistence of $\mathrm{Ca}_{\mathrm{v}} 1.3 \mathrm{Ca}^{2+}$ channels in mature outer hair cells supports outer hair cell afferent signaling. $J$ Neurosci 27:6442-6451.

Koesling D, Mergia E, and Russwurm M (2016) Physiological functions of NO-sensitive guanylyl cyclase isoforms. Curr Med Chem 23:2653-2665.

Koesling D, Russwurm M, Mergia E, Mullershausen F, and Friebe A (2004) Nitric oxidesensitive guanylyl cyclase: structure and regulation. Neurochem Int 45:813-819.

Kopp-Scheinpflug C, Pigott BM, and Forsythe ID (2015) Nitric oxide selectively suppresses IH currents mediated by HCN1-containing channels. J Physiol 593 1685-1700.

Kujawa SG and Liberman MC (2006) Acceleration of age-related hearing loss by early noise exposure: evidence of a misspent youth. $J$ Neurosci 26:2115-2123.

Kujawa SG and Liberman MC (2009) Adding insult to injury: cochlear nerve degeneration after "temporary" noise-induced hearing loss. J Neurosci 29: 14077-14085.

Lakso M, Pichel JG, Gorman JR, Sauer B, Okamoto Y, Lee E, Alt FW, and Westphal $\mathrm{H}$ (1996) Efficient in vivo manipulation of mouse genomic sequences at the zygote stage. Proc Natl Acad Sci USA 93:5860-5865.

Lehmann M, Pirinen E, Mirsaidi A, Kunze FA, Richards PJ, Auwerx J, and Hottiger MO (2015) ARTD1-induced poly-ADP-ribose formation enhances PPAR $\gamma$ ligand binding and co-factor exchange. Nucleic Acids Res 43:129-142.

Liberman MC (1980) Morphological differences among radial afferent fibers in the cat cochlea: an electron-microscopic study of serial sections. Hear Res 3:45-63.

Lin HW, Furman AC, Kujawa SG, and Liberman MC (2011) Primary neural degeneration in the guinea pig cochlea after reversible noise-induced threshold shift. J Assoc Res Otolaryngol 12:605-616. 
Marcon S and Patuzzi R (2008) Changes in cochlear responses in guinea pig with changes in perilymphatic $\mathrm{K}^{+}$. Part I: summating potentials, compound action potentials and DPOAEs. Hear Res 237:76-89.

Marcotti W and Kros CJ (1999) Developmental expression of the potassium current $I_{\mathrm{K}, \mathrm{n}}$ contributes to maturation of mouse outer hair cells. J Physiol 520:653-660.

Melcher JR and Kiang NY (1996) Generators of the brainstem auditory evoked potential in cat. III: identified cell populations. Hear Res 93:52-71.

Mergia E, Friebe A, Dangel O, Russwurm M, and Koesling D (2006) Spare guanylyl cyclase NO receptors ensure high NO sensitivity in the vascular system. J Clin Invest 116:1731-1737.

Mergia E, Russwurm M, Zoidl G, and Koesling D (2003) Major occurrence of the new $\alpha 2 \beta 1$ isoform of NO-sensitive guanylyl cyclase in brain. Cell Signal 15:189-195.

Michna M, Knirsch M, Hoda JC, Muenkner S, Langer P, Platzer J, Striessnig J, and Engel $\mathrm{J}(2003) \mathrm{Ca}_{\mathrm{v}} 1.3(\alpha 1 \mathrm{D}) \mathrm{Ca}^{2+}$ currents in neonatal outer hair cells of mice. J Physiol 553:747-758.

Möhrle D, Ni K, Varakina K, Bing D, Lee SC, Zimmermann U, Knipper M, and Rüttiger L (2016) Loss of auditory sensitivity from inner hair cell synaptopathy can be centrally compensated in the young but not old brain. Neurobiol Aging 44: $173-184$.

Moretti R, Leger P-L, Besson VC, Csaba Z, Pansiot J, Di Criscio L, Gentili A, Titomanlio L, Bonnin P, Baud O, et al. (2016) Sildenafil, a cyclic GMP phosphodiesterase inhibitor, induces microglial modulation after focal ischemia in the neonatal mouse brain. J Neuroinflammation 13:95

Moskalev AA, Aliper AM, Smit-McBride Z, Buzdin A, and Zhavoronkov A (2014) Genetics and epigenetics of aging and longevity. Cell Cycle 13:1063-1077.

Narui Y, Minekawa A, Iizuka T, Furukawa M, Kusunoki T, Koike T, and Ikeda K (2009) Development of distortion product otoacoustic emissions in C57BL/6J mice. Int $J$ Audiol 48:576-581.

Neitz A, Mergia E, Eysel UT, Koesling D, and Mittmann T (2011) Presynaptic nitric oxide/cGMP facilitates glutamate release via hyperpolarization-activated cyclic nucleotide-gated channels in the hippocampus. Eur J Neurosci 33:1611-1621.

Neitz A, Mergia E, Imbrosci B, Petrasch-Parwez E, Eysel UT, Koesling D, and Mittmann T (2014) Postsynaptic NO/cGMP increases NMDA receptor currents via hyperpolarization-activated cyclic nucleotide-gated channels in the hippocampus. Cereb Cortex 24:1923-1936.

Ohinata Y, Miller JM, and Schacht J (2003) Protection from noise-induced lipid peroxidation and hair cell loss in the cochlea. Brain Res 966:265-273.

Peak TC, Richman A, Gur S, Yafi FA, and Hellstrom WJG (2016) The role of PDE5 inhibitors and the NO/cGMP pathway in cancer. Sex Med Rev 4:74-84.

Porter NM, Thibault O, Thibault V, Chen KC, and Landfield PW (1997) Calcium channel density and hippocampal cell death with age in long-term culture. $J$ Neurosci 17:5629-5639.

Puel JL (1995) Chemical synaptic transmission in the cochlea. Prog Neurobiol 47: 449-476.

Ramakrishnan NA, Drescher MJ, Khan KM, Hatfield JS, and Drescher DG (2012) HCN1 and HCN2 proteins are expressed in cochlear hair cells: HCN1 can form a ternary complex with protocadherin $15 \mathrm{CD} 3$ and F-actin-binding filamin A or can interact with HCN2. J Biol Chem 287:37628-37646.

Ruel J, Bobbin RP, Vidal D, Pujol R, and Puel JL (2000) The selective AMPA receptor antagonist GYKI 53784 blocks action potential generation and excitotoxicity in the guinea pig cochlea. Neuropharmacology 39:1959-1973.

Ruel J, Chabbert C, Nouvian R, Bendris R, Eybalin M, Leger CL, Bourien J, Mersel M, and Puel JL (2008) Salicylate enables cochlear arachidonic-acid-sensitive NMDA receptor responses. J Neurosci 28:7313-7323.

Russwurm M, Behrends S, Harteneck C, and Koesling D (1998) Functional properties of a naturally occurring isoform of soluble guanylyl cyclase. Biochem $J$ 335: $125-130$

Russwurm M and Koesling D (2002) Isoforms of NO-sensitive guanylyl cyclase. Mol Cell Biochem 230:159-164.

Russwurm M, Mullershausen F, Friebe A, Jäger R, Russwurm C, and Koesling D (2007) Design of fluorescence resonance energy transfer (FRET)-based cGMP indicators: a systematic approach. Biochem J 407:69-77.

Rüttiger L, Singer W, Panford-Walsh R, Matsumoto M, Lee SC, Zuccotti A, Zimmermann U, Jaumann M, Rohbock K, Xiong H, et al. (2013) The reduced cochlear output and the failure to adapt the central auditory response causes tinnitus in noise exposed rats. PLoS One 8:e57247.

Rüttiger L, Zimmermann U, and Knipper M (2017) Biomarkers for hearing dysfunction: facts and outlook. ORL J Otorhinolaryngol Relat Spec 79:93-111.

Sanes DH and Constantine-Paton M (1985) The sharpening of frequency tuning curves requires patterned activity during development in the mouse, Mus musculus. $J$ Neurosci 5:1152-1166.

Scheiblich H and Bicker G (2016) Nitric oxide regulates antagonistically phagocytic and neurite outgrowth inhibiting capacities of microglia. Dev Neurobiol $\mathbf{7 6}$ $566-584$

Schiff M, Bénit P, Jacobs HT, Vockley J, and Rustin P (2012) Therapies in inborn errors of oxidative metabolism. Trends Endocrinol Metab 23:488-495.

Schindelin J, Arganda-Carreras I, Frise E, Kaynig V, Longair M, Pietzsch T, Preibisch S, Rueden C, Saalfeld S, Schmid B, et al. (2012) Fiji: an open-source platform for biological-image analysis. Nat Methods 9:676-682.

Seebacher T, Beitz E, Kumagami H, Wild K, Ruppersberg JP, and Schultz JE (1999) Expression of membrane-bound and cytosolic guanylyl cyclases in the rat inner ear. Hear Res 127:95-102.

Shen J, Harada N, Nakazawa H, Kaneko T, Izumikawa M, and Yamashita T (2006) Role of nitric oxide on ATP-induced $\mathrm{Ca}^{2+}$ signaling in outer hair cells of the guinea pig cochlea. Brain Res 1081:101-112.

Shen J, Harada N, Nakazawa H, and Yamashita T (2005) Involvement of the nitric oxide-cyclic GMP pathway and neuronal nitric oxide synthase in ATP-induced $\mathrm{Ca}^{2+}$ signalling in cochlear inner hair cells. Eur J Neurosci 21:2912-2922.
Shen J, Harada N, and Yamashita T (2003) Nitric oxide inhibits adenosine 5' triphosphate-induced $\mathrm{Ca}^{2+}$ response in inner hair cells of the guinea pig cochlea Neurosci Lett 337:135-138.

Shera CA and Guinan JJ, Jr (1999) Evoked otoacoustic emissions arise by two fundamentally different mechanisms: a taxonomy for mammalian OAEs. J Acoust Soc Am 105:782-798.

Shi X, Ren T, and Nuttall AL (2002) The electrochemical and fluorescence detection of nitric oxide in the cochlea and its increase following loud sound. Hear Res 164: $49-58$

Singer W, Zuccotti A, Jaumann M, Lee SC, Panford-Walsh R, Xiong H, Zimmermann U, Franz C, Geisler HS, Köpschall I, et al. (2013) Noise-induced inner hair cell ribbon loss disturbs central arc mobilization: a novel molecular paradigm for understanding tinnitus. Mol Neurobiol 47:261-279.

Stasch JP, Alonso-Alija C, Apeler H, Dembowsky K, Feurer A, Minuth T, Perzborn E, Schramm M, and Straub A (2002a) Pharmacological actions of a nove NO-independent guanylyl cyclase stimulator, BAY 41-8543: in vitro studies. $\mathrm{Br} J$ Pharmacol 135:333-343.

Stasch JP, Dembowsky K, Perzborn E, Stahl E, and Schramm M (2002b) Cardiovascular actions of a novel NO-independent guanylyl cyclase stimulator, BAY 41-8543: in vivo studies. $\mathrm{Br} \mathrm{J}$ Pharmacol 135:344-355.

Stasch JP and Evgenov OV (2013) Soluble guanylate cyclase stimulators in pulmonary hypertension. Handb Exp Pharmacol 218:279-313.

Tabuchi K and Hara A (2012) Implications of cytokines in cochlear pathophysiology, in Mechanical Stretch and Cytokines (Kamkin A and Kiseleva I eds) pp 189-199, Springer, Dordrecht, Netherlands.

Takeda-Nakazawa H, Harada N, Shen J, Kubo N, Zenner HP, and Yamashita T (2007) Hyposmotic stimulation-induced nitric oxide production in outer hair cells of the guinea pig cochlea. Hear Res 230:93-104.

Takumida M and Anniko M (2002) Nitric oxide in the inner ear. Curr Opin Neurol 15 $11-15$

Tan J, Rüttiger L, Panford-Walsh R, Singer W, Schulze H, Kilian SB, Hadjab S, Zimmermann U, Köpschall I, Rohbock K, et al. (2007) Tinnitus behavior and hearing function correlate with the reciprocal expression patterns of BDNF and Arg3.1/arc in auditory neurons following acoustic trauma. Neuroscience 145:715-726.

Tan WJT, Thorne PR, and Vlajkovic SM (2016) Characterisation of cochlear inflammation in mice following acute and chronic noise exposure. Histochem Cell Biol 146:219-230.

Thunemann M, Fomin N, Krawutschke C, Russwurm M, and Feil R (2013a) Visualization of cGMP with cGi biosensors. Methods Mol Biol 1020:89-120.

Thunemann M, Wen L, Hillenbrand M, Vachaviolos A, Feil S, Ott T, Han X, Fukumura D, Jain RK, Russwurm M, et al. (2013b) Transgenic mice for cGMP imaging. Circ Res 113:365-371.

Uthaiah RC and Hudspeth AJ (2010) Molecular anatomy of the hair cell's ribbon synapse. J Neurosci 30:12387-12399.

Viana LM, O'Malley JT, Burgess BJ, Jones DD, Oliveira CA, Santos F, Merchant SN, Liberman LD, and Liberman MC (2015) Cochlear neuropathy in human presbycusis: confocal analysis of hidden hearing loss in post-mortem tissue. Hear Res 327:78-88.

Wakabayashi K, Fujioka M, Kanzaki S, Okano HJ, Shibata S, Yamashita D, Masuda M, Mihara M, Ohsugi Y, Ogawa K, et al. (2010) Blockade of interleukin-6 signaling suppressed cochlear inflammatory response and improved hearing impairment in noise-damaged mice cochlea. Neurosci Res 66:345-352.

Weber T, Zimmermann U, Winter H, Mack A, Köpschall I, Rohbock K, Zenner HP, and Knipper M (2002) Thyroid hormone is a critical determinant for the regulation of the cochlear motor protein prestin. Proc Natl Acad Sci USA 99:2901-2906.

Wichmann C and Moser T (2015) Relating structure and function of inner hair cell ribbon synapses. Cell Tissue Res 361:95-114.

Winter H, Braig C, Zimmermann U, Engel J, Rohbock K, and Knipper M (2007) Thyroid hormone receptor $\alpha 1$ is a critical regulator for the expression of ion channels during final differentiation of outer hair cells. Histochem Cell Biol 128 $65-75$.

Yang W, Vethanayagam RR, Dong Y, Cai Q, and Hu BH (2015) Activation of the antigen presentation function of mononuclear phagocyte populations associated with the basilar membrane of the cochlea after acoustic overstimulation. Neuroscience 303:1-15.

Yi E, Roux I, and Glowatzki E (2010) Dendritic HCN channels shape excitatory postsynaptic potentials at the inner hair cell afferent synapse in the mammalian cochlea. J Neurophysiol 103:2532-2543.

Yukawa H, Shen J, Harada N, Cho-Tamaoka H, and Yamashita T (2005) Acute effects of glucocorticoids on ATP-induced $\mathrm{Ca}^{2+}$ mobilization and nitric oxide production in cochlear spiral ganglion neurons. Neuroscience 130:485-496.

Zampini V, Johnson SL, Franz C, Lawrence ND, Münkner S, Engel J, Knipper M, Magistretti J, Masetto S, and Marcotti W (2010) Elementary properties of Ca 1.3 $\mathrm{Ca}\left({ }^{2+}\right)$ channels expressed in mouse cochlear inner hair cells. $J$ Physiol 588: $187-199$

Zheng J, Shen W, He DZ, Long KB, Madison LD, and Dallos P (2000) Prestin is the motor protein of cochlear outer hair cells. Nature 405:149-155.

Zuccotti A, Kuhn S, Johnson SL, Franz C, Singer W, Hecker D, Geisler HS, Köpschall I, Rohbock K, Gutsche K, et al. (2012) Lack of brain-derived neurotrophic factor hampers inner hair cell synapse physiology, but protects against noise-induced hearing loss. J Neurosci 32:8545-8553.

Address correspondence to: Dr. Marlies Knipper, HNO-Klinik, Universität Tübingen, Elfriede-Aulhorn-Straße 5, 72076 Tübingen, Germany. E-mail: marlies.knipper@uni-tuebingen.de; or Dr. Lukas Rüttiger, HNO-Klinik, Universität Tübingen, Elfriede-Aulhorn-Straße 5, 72076 Tübingen, Germany. E-mail: lukas.ruettiger@uni-tuebingen.de 